\title{
Different Solution Strategies for Solving Epidemic Model in Imprecise Environment
}

\author{
Animesh Mahata $\mathbb{D D}^{1,2}$ Sankar Prasad Mondal ${ }^{1},{ }^{3}$ Ali Ahmadian $\mathbb{D}^{4},{ }^{4}$ Fudiah Ismail $\mathbb{D},{ }^{4}$ \\ Shariful Alam, ${ }^{1}$ and Soheil Salahshour $\mathbb{C i}^{5}$ \\ ${ }^{1}$ Department of Mathematics, Indian Institute of Engineering Science and Technology, Shibpur, Howrah, West Bengal 711103, India \\ ${ }^{2}$ Department of Mathematics, Netaji Subhash Engineering College, Techno City, Garia, Kolkata, West Bengal 700152, India \\ ${ }^{3}$ Department of Mathematics, Midnapore College (Autonomous), Midnapore, West Midnapore, West Bengal 721101, India \\ ${ }^{4}$ Laboratory of Computational Sciences and Mathematical Physics, Institute for Mathematical Research (INSPEM), \\ Universiti Putra Malaysia (UPM), 43400 Serdang, Selangor, Malaysia \\ ${ }^{5}$ Young Researchers and Elite Club, Mobarakeh Branch, Islamic Azad University, Mobarakeh, Iran \\ Correspondence should be addressed to Ali Ahmadian; ahmadian.hosseini@gmail.com
}

Received 6 February 2017; Revised 6 June 2017; Accepted 15 January 2018; Published 13 May 2018

Academic Editor: Carla Pinto

Copyright (C) 2018 Animesh Mahata et al. This is an open access article distributed under the Creative Commons Attribution License, which permits unrestricted use, distribution, and reproduction in any medium, provided the original work is properly cited.

We study the different solution strategy for solving epidemic model in different imprecise environment, that is, a SusceptibleInfected-Susceptible (SIS) model in imprecise environment. The imprecise parameter is also taken as fuzzy and interval environment. Three different solution procedures for solving governing fuzzy differential equation, that is, fuzzy differential inclusion method, extension principle method, and fuzzy derivative approaches, are considered. The interval differential equation is also solved. The numerical results are discussed for all approaches in different imprecise environment.

\section{Introduction}

1.1. Modeling with Impreciseness. The aim of mathematical modeling is to imitate some real world problems as far as possible. The presence of imprecise variable and parameters in practical problems in the field of biomathematical modeling became a new area of research in uncertainty modeling. So, the solution procedure of such problems is very important. If the solution of said problems with uncertainty is developed, then, many real life models in different fields with imprecise variable can be formulated and solved easily and accurately.

1.2. Fuzzy Set Theory and Differential Equation. Differential equations may arise in the mathematical modeling of real world problems. But when the impreciseness comes to it, the behavior of the differential equation is altered. The solution procedures are taken in different way. In this paper we take two types of imprecise environments, fuzzy and interval, and find their exact solution. In 1965, Zadeh [1] published the first of his papers on the new theory of Fuzzy Sets and Systems. After that Chang and Zadeh [2] introduced the concept of fuzzy numbers. In the last few years researchers have been giving their great contribution on the topic of fuzzy number research [3-5]. As for the application of the fuzzy set theory applied in fuzzy equation [6], fuzzy differential equation [7], fuzzy integrodifferential equation [8-10], fuzzy integral equation [11], and so on were developed.

1.3. Different Approaches for Solving Fuzzy Differential Equation. The application of differential equations has been widely explored in various fields like engineering, economics, biology, and physics. For constructing different types of problems in real life situation the fuzzy set theory plays an important role. The applicability of nonsharp or imprecise concept is very useful for exploring different sectors for its applicability. A differential equation can be called fuzzy differential equation if (1) only the coefficient (or coefficients) of the differential equation is fuzzy valued number, (2) only 
TABLE 1

\begin{tabular}{|c|c|c|}
\hline & Name of the theory & Some references \\
\hline \multirow{18}{*}{$\begin{array}{l}\text { Fuzzy differential } \\
\text { equation }\end{array}$} & \multirow{2}{*}{ Fuzzy differential inclusion } & Baidosov [12], \\
\hline & & Hüllermeier [13] \\
\hline & Zadeh's Extension principle & $\begin{array}{l}\text { Oberguggenberger and Pittschmann [14], } \\
\text { Buckley and Feuring [15] }\end{array}$ \\
\hline & \multicolumn{2}{|l|}{$\begin{array}{l}\text { Approach using derivative of fuzzy valued } \\
\text { functions }\end{array}$} \\
\hline & Dubois-Prade derivative & Dubois and Prade [16] \\
\hline & Puri-Ralescu derivative & Puri and Ralescu [17] \\
\hline & Goetschel-Voxman derivative & Goetschel Jr. and Voxman [18] \\
\hline & Friedman-Ming-Kandel derivative & Friedman et al. [19] \\
\hline & Seikkala derivative & Seikkala $[20]$ \\
\hline & SGH derivative & Bede and Gal [21] \\
\hline & Same-order and reverse-order derivative & Zhang and Wang [22] \\
\hline & $\pi$-derivative & Chalco-Cano et al. [23] \\
\hline & gH-derivative & Stefanini and Bede [24] \\
\hline & g-derivative & Bede and Stefanini [25] \\
\hline & $\mathrm{H}_{2}$-derivative & Mazandarani and Najariyan [26] \\
\hline & Interactive derivative & de Barros and Santo Pedro [27] \\
\hline & gr-derivative & Mazandarani et al. [28] \\
\hline & $\begin{array}{l}\text { Approach using fuzzy bunch of real valued } \\
\text { functions instead of fuzzy valued functions }\end{array}$ & Gasilov et al. [29-32], Amrahov et al. [33] \\
\hline
\end{tabular}

the initial value (or values) or boundary value (or values) is fuzzy valued number, (3) the forcing term is fuzzy valued function, and (4) all the conditions (1), (2), and (3) or their combination is present on the differential equation.

There exist two types of strategies for solving the FDEs, which are as follows:

(a) Zadeh's extension principle method.

(b) Differential inclusion method.

(c) Approach using derivative of fuzzy valued functions.

(d) Approach using fuzzy bunch of real valued functions instead of fuzzy valued functions.

Now we look on some different procedure and concepts of derivation in Table 1.

There exist different numerical techniques [34-36] for solving the fuzzy differential equation. The techniques are not fully similar to any differential equation solving techniques.

In this paper we only study the first three approaches.

1.4. Interval Differential Equation. An interval number is itself an imprecise parameter. Because the value is not a crisps number, the value lies between two crisp numbers. When we take any parameter, may be coefficients or initial condition or both, of a differential equation then the interval differential equation comes. The basic behaviors of that number are different from a crisp number. Hence, the calculus of those types numbers valued functions is different. So we need to study the differential equation in these environments. From the time that Moore [37] and Markov [38] as the pioneers introduced the interval analysis and related notions, several monographs and papers were devoted to connect the fuzzy analysis and interval analysis [39], but, the later one was not wellrealized and applicable to model dynamical systems. After introducing generalized Hukuhara differentiability, different perspectives, which leaded to nice schemes and strategies to achieve the solutions, were discussed in the literature [40-43]. Lupulescu in [44] developed the notions of RLand Caputo-types derivatives for interval-valued functions. Salahshour et al. $[45,46]$ proposed a nonsingular kernel and conformable fractional derivative for interval differential equations of fractional order. Recently interval differential equation is studied by da Costa et al. [47] and Gasilov and Emrah Amrahov [48].

\subsection{Work Done Using Fuzzy Differential Equation and Interval} Differential Equation on Biomathematical Problem. Fuzzy differential equation and biomathematics are not new topics. A lot of research was done in this field. For instance, check [49-68]. Many authors consider interval parameter with differential equation in biomathematical model. For presence of interval parameter the equation becomes interval differential equation. Using the property of interval number they solve the concerned model and discuss the behavior. Pal and Mahapatra [62] consider a bioeconomic modeling of two-prey and one-predator fishery model with optimal harvesting policy through hybridization approach in interval environment. Similarly, optimal harvesting of prey-predator system with interval biological parameters is discussed in [63]. Sharma and Samanta consider optimal harvesting of 
a two species competition model with imprecise biological parameters in [69]. Although Barros et al. [70] studied SIS model in fuzzy environment using fuzzy differential inclusion still we can study the model in different environments by different approaches.

1.6. Motivation. Impreciseness comes in every model for biological system. The necessity for taking some parameter as imprecise in a model is an important topic today. There are so many works done on biological model with imprecise data. Sometimes parameters are taken as fuzzy and sometimes it is an interval. Our main aim is modeled as a biological problem associated with differential equation with some imprecise parameters. Thus fuzzy differential equation and imprecise differential equation are important. Now we can concentrate some previous works on biological modeling in imprecise environments:

1.7. Novelties. Although some developments are done, some new and interesting research works have been done by ourselves, which are mentioned as follows:

(i) SIS model is studied in imprecise environment.

(ii) The fuzzy and interval environments are taken for analyses in the model.

(iii) The governing fuzzy differential equation is solved by three approaches: fuzzy differential inclusion, extension principal, and fuzzy derivative approaches.

(iv) The SIS model is solved by reducing the dimension of the model for fuzzy cases. For these reasons we use completely correlated fuzzy number.

(v) Numerical examples are taken for showing the comparative view of different approaches.

Moreover, we can say all developments can help for the researchers who are engaged with uncertainty modeling, differential equation, and biological system if fuzzy parameters are assumed in the models. One can model and find the solution on any biological model with fuzzy and differential equation by the same approaches.

\section{Basic Definitions}

\subsection{Definition}

Definition 1 (fuzzy set). Let $\widetilde{F}$ be a fuzzy set which is defined by a pair $\left(U, \mu_{\widetilde{F}}(x)\right)$, where $U$ is a nonempty universal set and

$$
\mu_{\widetilde{F}}(x): U \longrightarrow[0,1]
$$

For each $x \in U, \mu_{\widetilde{F}}(x)$ is the grade of membership function of $\widetilde{F}$.

Definition 2 (fuzzy number in trapezoidal form). A fuzzy number in trapezoidal form represented by three points like as $\widetilde{K}=\left(K_{1}, K_{2}, K_{3}, K_{4}\right)$ and the presentation can be illustrated as membership function as

$$
\mu_{\widetilde{K}}(y)= \begin{cases}0, & y \leq K_{1} \\ \frac{y-K_{1}}{K_{2}-F_{1}}, & K_{1} \leq y \leq K_{2} \\ 1, & y=F_{2} \\ \frac{K_{4}-y}{K_{4}-K_{3}}, & K_{3} \leq y \leq K_{4} \\ 0, & y \geq K_{4} .\end{cases}
$$

Definition 3 ( $\alpha$-cut of a fuzzy set). The $\alpha$-cut of $\widetilde{K}=$ $\left(K_{1}, K_{2}, K_{3}, K_{4}\right)$ is given by

$$
\begin{aligned}
& K_{\alpha}=\left[K_{1}+\alpha\left(K_{2}-K_{1}\right), K_{4}-\alpha\left(K_{4}-K_{3}\right)\right] \\
& \forall \alpha \in[0,1] .
\end{aligned}
$$

Definition 4 (correlated fuzzy number: [71]). Let $\widetilde{A}_{f}$ and $\widetilde{B}_{f}$ are two fuzzy sets whose membership function is written as follows: $\mu_{\widetilde{A}_{f}}(x)$ and $\mu_{\widetilde{B}_{f}}(x)$. Then there exist $d, e \in R$ with $q \neq 0$ such that their joint possibility distribution is given by

$$
\begin{aligned}
\mu_{\widetilde{C}_{f}}(x, y) & =\mu_{\widetilde{A}_{f}}(x) \chi_{\{d x+e=y\}}(x, y) \\
& =\mu_{\widetilde{B}_{f}}(x) \chi_{\{d x+e=y\}}(x, y),
\end{aligned}
$$

where $\chi_{\{d x+e=y\}}(x, y)=\{1$, if $d x+e=y$; 0 , if $d x+e \neq y\}$ is the characteristic function of the line $\left\{(x, y) \in R^{2}: d x+e=y\right\}$.

In this case we have $\left(\widetilde{C}_{f}\right)_{\alpha}=\left\{(x, d x+e=y) \in R^{2}\right.$ : $\left.x=(1-l) A_{01}(\alpha)+l A_{02}(\alpha), l \in[0,1]\right\}$, where $\left(\widetilde{A}_{f}\right)_{\alpha}=$ $\left[A_{01}(\alpha), A_{02}(\alpha)\right],\left(\widetilde{B}_{f}\right)_{\alpha}=d\left(\widetilde{A}_{f}\right)_{\alpha}+e$, for any $\alpha \in[0,1]$. Moreover if $d \neq 0$,

$$
\mu_{\widetilde{B}_{f}}(x)=\mu_{\widetilde{A}_{f}}\left(\frac{x-e}{d}\right), \quad \forall x \in R .
$$

Definition 5 (correlated trapezoidal fuzzy number). Two trapezoidal fuzzy numbers $\widetilde{A}=\left(a_{1}, a_{2}, a_{3}, a_{4}\right)$ and $\widetilde{B}=$ $\left(b_{1}, b_{2}, b_{3}, b_{4}\right)$ are said to be correlated if $a_{1} \triangle b_{1}=a_{2} \triangle b_{2}=$ $a_{3} \triangle b_{3}=a_{4} \triangle b_{4}=q$, where $\Delta$ is arbitrary operation and $a_{1}, a_{2}, a_{3}, a_{4}, b_{1}, b_{2}, b_{3}, b_{4}, q$ is constant.

Example 6. Let a trapezoidal fuzzy number be like $\widetilde{A}=$ $(1 / 5,2 / 5,3 / 5,4 / 5)$. Now we have to find another trapezoidal fuzzy number $\widetilde{B}$ that is correlated to $\widetilde{A}$.

Let $\widetilde{B}$ be of the form $\left(b_{1}, b_{2}, b_{3}, b_{4}\right)$.

So clearly we have $b_{1}+1 / 5=b_{2}+2 / 5=b_{3}+3 / 5=$ $b_{4}+4 / 5=1$

So, $b_{1}=4 / 5, b_{2}=3 / 5, b_{3}=2 / 5, b_{4}=1 / 5$.

So we can write $\widetilde{B}=(4 / 5,3 / 5,2 / 5,1 / 5)$, but here $4 / 5 \nless$ $3 / 5 \nless 2 / 5 \nless 1 / 5$. 4/5).

We can write it in modified form as $\widetilde{B}=(1 / 5,2 / 5,3 / 5$,

Note 7 (use of correlated fuzzy number). There can be a basic question arising here, which is why we take correlated fuzzy 
variables. Fuzzy number can be employed and applied in various fields for various models. Sometimes for simplification of a model, we give a transformation so that the operation between two variables becomes unit. Now, if the initial condition or the solution is defined as a fuzzy parameter then the certain operation on this quantity is obviously a unit number. Otherwise, the importance of using a correlated fuzzy number is to take the data in fewer amounts, which can be very helpful for calculation.

Definition 8 (strong and weak solution of fuzzy differential equation). Consider the first order fuzzy differential equation $d x / d t=f(k, x(t))$ with $\left(t_{0}\right)=x_{0}$. Here $k$ or (and) $x_{0}$ is fuzzy number(s).

Let the solution (the solution comes from any method) of the above FDE be $\tilde{x}(t)$ and its $\alpha$-cut be $x(t, \alpha)=$ $\left[x_{1}(t, \alpha), x_{2}(t, \alpha)\right]$.

If $x_{1}(t, \alpha) \leq x_{2}(t, \alpha) \forall \alpha \in[0,1]$ then $\widetilde{x}(t)$ is called strong solution; otherwise $\widetilde{x}(t)$ is called weak solution and in that case the $\alpha$-cut of the solution is given by

$$
\begin{gathered}
x(t, \alpha)=\left[\min \left\{x_{1}(t, \alpha), x_{2}(t, \alpha)\right\},\right. \\
\left.\max \left\{x_{1}(t, \alpha), x_{2}(t, \alpha)\right\}\right] .
\end{gathered}
$$

Definition 9 (interval number). An interval number $I$ is represented by closed interval $\left[I_{l}, I_{u}\right]$ and defined by $I=$ $\left[I_{l}, I_{u}\right]=\left\{x: I_{l} \leq x \leq I_{u}, x \in \mathfrak{R}\right\}$, where $\mathfrak{R}$ is the set of real numbers and $I_{l}$ and $I_{u}$ are the left and right boundary of the interval number, respectively.

\section{Method for Solving Fuzzy Differential Equation}

Let us consider the differential equation

$$
x^{\prime}(t)=f(t, k, x(t)), \quad x\left(t_{0}\right)=x_{0}, a \leq t \leq b,
$$

where $k$ is constant, $x_{0}$ is initial condition, and $f(t, k, x(t))$ is the function which may be linear or nonlinear.

The differential equation (7) can be fuzzy differential equation if

(i) $x_{0}$, that is, initial condition, is fuzzy number.

(ii) $k$, that is, coefficient, is a fuzzy number.

(iii) $x_{0}$ and $k$, that is, initial condition and coefficient, are both fuzzy numbers.

3.1. Differential Inclusion Method for Solving Fuzzy Differential Equation. There are the papers where the concept of fuzzy differential equations is understood as the family of differential inclusions. For details see Agarwal et al. [72, 73], Diamond [74, 75], Laksmikantham et al. [76], and Lakshmikantham and Tolstonogov [77]. This new approach allowed considering some interesting aspects of fuzzy differential equations such as periodicity, Lyapunov stability, regularity of solution sets, attraction, and variation of constants formula (see [74, $75,78,79])$. Also the numerical methods for FDEs have been developed in Hüllermeier [13, 80] and Ma et al. [81].
Let us assume the following differential inclusion is of the form

$$
u^{\prime}(t) \in g(t, u(t))
$$

with $u(0)=u_{0} \in U_{0}$.

$g:[0, T] \times R^{n} \rightarrow F^{n}$ is a set valued function and $U_{0} \in F^{n}$ (here $F^{n}$ is space of fuzzy numbered valued functions). We have to solve $u\left(\cdot, u_{0}\right)$ of $(8)$ with $u_{0} \in U_{0}$ provided:

(a) The function $u\left(\cdot, u_{0}\right)$ is absolutely continuous in $[0, T]$.

(b) The function $u\left(\cdot, u_{0}\right)$ satisfies (8) for $t \in[0, T]$.

Now we denote the attainable set at time $t \in[0, T]$ which is subset of $R^{n}$ associated with the problem (8) defined by $A\left(t, U_{0}\right)=\left\{u\left(t, u_{0}\right): u\left(\cdot, u_{0}\right)\right.$ which is solution of $\left.(8)\right\}$.

In fuzzy environment dynamical system the problem (8) can be formed as

$$
u^{\prime}(t) \in \widetilde{g}(t, u(t)) \quad u(0)=u_{0} \in \widetilde{U}_{0},
$$

where $\widetilde{g}:[0, T] \times R^{n} \rightarrow F^{n}$ is a fuzzy set valued function and $U_{0} \in F^{n}$.

According to Hüllermeier [13] the fuzzy initial value problem can be formed as family of differential inclusion given as

$$
u_{\alpha}^{\prime}(t) \in g\left(t, u_{\alpha}(t)\right) \quad u_{\alpha}(0) \in U_{0 \alpha} \text { with } \alpha \in[0,1],
$$

where $g\left(t, u_{\alpha}(t)\right)$ are the $\alpha$-cuts of fuzzy set $\widetilde{g}(t, u(t))$.

Here the attainable sets related to the problem (10) can be defined by $A_{\alpha}\left(t, U_{0 \alpha}, \cdot\right)=\left\{u_{\alpha}(t): u_{\alpha}\left(\cdot, u_{\alpha}\right)\right.$ which is a solution of $(10)$ in $[0, T]\}$.

Hence there is fuzzy interval $U(t)=A\left(t, U_{0}, \cdot\right)$ which is a fuzzy solution of (10) via differential inclusion if for all $t \epsilon$ $[0, T]$ the collection of $\alpha$-cuts $\left\{A_{\alpha}\left(t, U_{0 \alpha}, \cdot\right)\right\}_{\alpha \in[0,1]}$ satisfies the condition of the following theorem.

Theorem 10 (see [71]). Let $\left\{A_{\alpha} \subseteq R \mid 0 \leq \alpha \leq 1\right\}$ be family of sets satisfying the following:

(i) $A_{\alpha}$ is a compact and convex interval, for all $0 \leq \alpha \leq 1$;

(ii) $A_{\beta} \subseteq A_{\alpha}$ for $0 \leq \alpha \leq \beta \leq 1$;

(iii) $A_{\alpha}=\bigcap_{i=1} A_{\alpha_{i}}$ for any nondecreasing sequence $\alpha_{i} \rightarrow \alpha$ in $[0,1]$.

Then there is a unique fuzzy interval $u \in F_{c}$ such that $[u]^{\alpha}=$ $Y_{\alpha}$. Conversely, the $\alpha$-cuts sets $[u]^{\alpha}$ for any $u \in F_{c}$ satisfy these conditions.

Therefore, we have the $\alpha$ solution $u_{\alpha}:[0, T] \rightarrow R^{n}$ of (9) if it is a solution of (10).

Theorem 11 (see [71]). Suppose $E, F \in \varepsilon(R)$ are completely correlated fuzzy numbers; let $G$ be their joint possibility distribution and $f: R^{2} \rightarrow R^{2}$ be a continuous function; then $\left[f_{C}(E, F)\right]^{\alpha}=f\left([C]^{\alpha}\right)$.

Theorem 12 (see [71]). For all $\left(u_{0}, v\right) \in R^{2}$ there exists a unique solution to (10) in $\left[0, T_{0}\right]$. Then the solution of the problem (7) 
via extension principle when $U_{0}$ and $Y$ are noninteractive, and when $U_{0}$ and $Y$ are completely correlated satisfies the following relation $\left[\left(L_{t}\right)_{c}\left(U_{0}, V\right)\right]^{\alpha} \subseteq\left[\left(L_{t}\right)_{J_{p}}\left(U_{0}, V\right)\right]^{\alpha}$, for all $\alpha \in[0,1]$, where $J_{p}\left(u_{0}, v\right)=\min \left(\mu_{U_{0}}\left(u_{0}\right), \mu_{V}(v)\right)$, meaning $J_{p}$ is the joint possibility distribution of the noninteractive fuzzy numbers $U_{0}, V$.

3.2. Extension Principle for Solving Fuzzy Differential Equation. Extension principle is a method by which we can easily find the solution of a fuzzy differential equation. Some researchers considered this method to find the solution of fuzzy differential equations [82-84].

Definition 13 (extension principle on fuzzy sets). Suppose that we have some usual sets $X_{R}$ and choose some fuzzy sets $\widetilde{A} \in F S\left(X_{R}\right)$.

The extension principle for fuzzy sets states that if $F(\widetilde{A}) \in$ $F S\left(Y_{R}\right)$ such that $y \in X_{R}$,

$$
\begin{aligned}
\mu_{F(\widetilde{A})}(y) \\
= \begin{cases}\sup \left\{\mu_{\widetilde{A}}(x): x \in F^{-1}\{y\}\right\}, & \text { if } y \in \operatorname{Range}(F) \\
0, & \text { if } y \notin \operatorname{Range}(F)\end{cases}
\end{aligned}
$$

and for every $\widetilde{B} \in F S(Y), F^{-1}(\widetilde{B})$ is defined in the following way

$$
\mu_{F^{-1}(\widetilde{B})}(x)=\mu_{\widetilde{B}}(F(x))
$$

for every $x \in X_{R}$.

Example 14. Let $\widetilde{A}$ be a fuzzy set where membership function is written as

$$
\mu_{\widetilde{A}}(x)= \begin{cases}0 & \text { if } x \leq 3 \\ x-3 & \text { if } 3 \leq x<4 \\ 1 & \text { if } x=4 \\ \frac{6-x}{2} & \text { if } 4<x \leq 6 \\ 0 & \text { if } x \geq 6 .\end{cases}
$$

Let us choose a function $F(x)=2 x+3$.

Now by Zadeh's extension principle, $F(\widetilde{A})$ can be determined and its membership function is written as

$$
\mu_{F(\widetilde{A})}(y)= \begin{cases}0 & \text { if } x \leq 9 \\ \frac{y-9}{2} & \text { if } 9 \leq y<11 \\ 1 & \text { if } y=11 \\ \frac{15-y}{4} & \text { if } 11<y \leq 15 \\ 0 & \text { if } y \geq 15 .\end{cases}
$$

Method 15 (solution of fuzzy differential equation using extension principle). Let us consider the fuzzy initial value problem (FIVP)

$$
u^{\prime}(t)=g(t, u(t)), \quad \tilde{u}\left(t_{0}\right)=\tilde{u}_{0}, a \leq t \leq b .
$$

If we denote

$$
\begin{aligned}
& {[\tilde{u}(t)]^{\alpha}=\left[u_{1}^{\alpha}(t), u_{2}^{\alpha}(t)\right],} \\
& {\left[\tilde{u}_{0}\right]^{\alpha}=\left[u_{0,1}^{\alpha}, u_{0,2}^{\alpha}\right],} \\
& {[f(t, \tilde{x}(t))]^{\alpha}} \\
& \quad=\left[g_{1}^{\alpha}\left(t, u_{1}^{\alpha}(t), u_{2}^{\alpha}(t)\right), g_{2}^{\alpha}\left(t, u_{1}^{\alpha}(t), u_{2}^{\alpha}(t)\right)\right] .
\end{aligned}
$$

By using the extension principle we have the membership function

$$
g(t, u(t))(s)=\sup \{u(t)(\tau) \mid s=g(t, \tau)\}, \quad s \in R .
$$

The result $g(t, x(t))$ is a fuzzy function.

And

$$
\begin{aligned}
& g_{1}^{\alpha}\left(t, u_{1}^{\alpha}(t), u_{2}^{\alpha}(t)\right) \\
& \quad=\min \left\{g(t, u) \mid u \in\left[u_{1}^{\alpha}(t), u_{2}^{\alpha}(t)\right]\right\}, \\
& g_{2}^{\alpha}\left(t, u_{1}^{\alpha}(t), u_{2}^{\alpha}(t)\right) \\
& \quad=\max \left\{g(t, u) \mid u \in\left[u_{1}^{\alpha}(t), u_{2}^{\alpha}(t)\right]\right\} .
\end{aligned}
$$

3.3. Fuzzy Derivative and Solution of Fuzzy Differential Equation by Fuzzy Derivative Approach. Bede and Gal [85] presented a concept of generalized Hukuhara differentiability of fuzzy valued map-pings, which permits them to obtain the solutions of FDEs with a diminishing diameter of solutions values. This was followed up in the literature [8591]. This comprehensive definition allows us to resolve the disadvantages of the previous fuzzy derivatives. Indeed, the strongly generalized derivative is defined for a larger class of fuzzy number valued functions in the case of the Hukuhara derivative.

Before going to the fuzzy differential equation approach we first know the following definition.

Definition 16 (generalized Hukuhara difference). The generalized Hukuhara difference of two fuzzy numbers $p, q \in \mathfrak{R}_{\mathscr{F}}$ is defined as follows:

$$
p \Theta_{g} q=r \Longleftrightarrow\left\{\begin{array}{l}
\text { (i) } p=q \oplus r \\
\text { or (ii) } p=q \oplus(-1) r .
\end{array}\right.
$$

Consider $[r]_{\alpha}=\left[r_{1}(\alpha), r_{1}(\alpha)\right]$; then $r_{1}(\alpha)=\min \left\{p_{1}(\alpha)-\right.$ $\left.q_{1}(\alpha), p_{2}(\alpha)-q_{2}(\alpha)\right\}$ and $r_{1}(\alpha)=\max \left\{p_{1}(\alpha)-q_{1}(\alpha), p_{2}(\alpha)-\right.$ $\left.q_{2}(\alpha)\right\}$.

Here the parametric representation of a fuzzy valued function $G:[a, b] \rightarrow \mathfrak{R}_{\mathscr{F}}$ is expressed by

$$
\begin{aligned}
{[G(t)]_{\alpha}=\left[G_{1}(t, \alpha), G_{2}(t, \alpha)\right], } & \\
& t \in[a, b], \alpha \in[0,1] .
\end{aligned}
$$


Definition 17 (generalized Hukuhara derivative on a fuzzy function). The generalized Hukuhara derivative of a fuzzy valued function $G:(a, b) \rightarrow \mathfrak{R}_{\mathscr{F}}$ at $t_{0}$ is defined as

$$
G^{\prime}\left(t_{0}\right)=\lim _{h \rightarrow 0} \frac{G\left(t_{0}+h\right) \Theta_{g} G\left(\ominus_{g}\right)}{h} .
$$

If $G^{\prime}\left(t_{0}\right) \in \mathfrak{R}_{\mathscr{F}}$ satisfying (21) exists, we say that $G$ is generalized Hukuhara differentiable at $t_{0}$.

Also we say that $G(t)$ is (i)-gH differentiable at $t_{0}$ if

$$
\left[G^{\prime}\left(t_{0}\right)\right]_{\alpha}=\left[G_{1}^{\prime}\left(t_{0}, \alpha\right), G_{2}^{\prime}\left(t_{0}, \alpha\right)\right]
$$

and $G(t)$ is (ii)-gH differentiable at $t_{0}$ if

$$
\left[G^{\prime}\left(t_{0}\right)\right]_{\alpha}=\left[G_{2}^{\prime}\left(t_{0}, \alpha\right), G_{1}^{\prime}\left(t_{0}, \alpha\right)\right] .
$$

Method 18 (solution of fuzzy differential equation using fuzzy differential equation approach). Consider the fuzzy differential equation taking in (15).

We have the following two cases.

Case 1. If we consider $u^{\prime}(t)$ in the first from (i), then we have to solve the following system of ODEs:

$$
\begin{array}{ll}
\frac{d}{d t}\left(u_{1}^{\alpha}(t)\right)=g_{1}^{\alpha}\left(t, u_{1}^{\alpha}(t), u_{2}^{\alpha}(t)\right), & u_{1}^{\alpha}\left(t_{0}\right)=u_{0,1}^{\alpha} \\
\frac{d}{d t}\left(u_{2}^{\alpha}(t)\right)=g_{2}^{\alpha}\left(t, u_{1}^{\alpha}(t), u_{2}^{\alpha}(t)\right), & u_{2}^{\alpha}\left(t_{0}\right)=u_{0,2}^{\alpha} .
\end{array}
$$

Case 2. If we consider $u^{\prime}(t)$ in the first from (ii), then we have to solve the following system of ODEs:

$$
\begin{array}{ll}
\frac{d}{d t}\left(u_{1}^{\alpha}(t)\right)=g_{2}^{\alpha}\left(t, u_{1}^{\alpha}(t), u_{2}^{\alpha}(t)\right), & u_{1}^{\alpha}\left(t_{0}\right)=u_{0,1}^{\alpha} \\
\frac{d}{d t}\left(u_{2}^{\alpha}(t)\right)=g_{1}^{\alpha}\left(t, u_{1}^{\alpha}(t), u_{2}^{\alpha}(t)\right), & u_{2}^{\alpha}\left(t_{0}\right)=u_{0,2}^{\alpha} .
\end{array}
$$

In both cases, we should ensure that the solution $\left[u_{1}^{\alpha}(t), u_{2}^{\alpha}(t)\right]$ is valid level sets of a fuzzy number valued function and $\left[(d / d t)\left(u_{1}^{\alpha}(t)\right),(d / d t)\left(u_{2}^{\alpha}(t)\right)\right]$ are valid level sets of a fuzzy valued function.

\section{Model Formulation on Epidemic}

There are so many mathematical models in biology; SIS model is an important model of them. In a given species population at time $t$, let $S(t)$ be the number of susceptible, which means the number of those who can be infected, and $I(t)$ be the number of infected persons in the species population. In this model, a susceptible species can become infected at a rate proportional to $S(t) I(t)$ and an infected species can recover and become susceptible again at a rate of $\gamma I(t)$ so that the model can be formulated as follows:

$$
\begin{aligned}
& \frac{d S(t)}{d t}=-\beta S(t) I(t)+\gamma I(t) \\
& \frac{d I(t)}{d t}=\beta S(t) I(t)-\gamma I(t),
\end{aligned}
$$

where $S(t)=S_{0} I(t)=I_{0}$ at $t=0$ is the initial condition.
Here a susceptible $S(t)$ can become infected $I(t)$ at rate proportional of SI and on infected can recover and become susceptible again at a rate proportional to $I$.

$S(0)+I(0)=N(0)$ (total number of population).

Now taking $S(t) / N(t)=s(t), I(t) / N(t)=i(t)$, the model can be written as

$$
\begin{aligned}
& \frac{d s(t)}{d t}=-m s(t) i(t)+\gamma i(t) \\
& \frac{d i(t)}{d t}=m s(t) i(t)-\gamma i(t),
\end{aligned}
$$

where $m=\beta N(t)$ with initial condition $s(t)+i(t)=1$.

Note 19 (dimension less of a model). Sometimes for a mathematical model, it is critical to find the dynamical behavior. However, the dependent variables in the model are connected with another dependent variable, which makes the finding of the behavior complicated. In this regard, there is some criterion in which we can eliminate the conditions and make the model more simple and which is very easy to solve. According to these circumstances, we reduce the dimension of the above model.

The crisp solution of the above system of equations is written in two different cases.

Case 1 (when $p=m-\gamma \neq 0$ ). In this case the solution can be written as

$$
\begin{aligned}
& s(t)=\frac{i_{0} e^{p t}(m-p)+p-i_{0} m}{i_{0} m\left(e^{p t}-1\right)+p}, \\
& i(t)=\frac{i_{0} p e^{p t}}{i_{0} m\left(e^{p t}-1\right)+p} .
\end{aligned}
$$

Case 2 (when $p=m-\gamma=0$ ). In this case the solution can be written as

$$
\begin{aligned}
& s(t)=\frac{1+i_{0}(m t-1)}{1+m t i_{0}}, \\
& i(t)=\frac{i_{0}}{1+m t i_{0}} .
\end{aligned}
$$

Note 20. May be someone will ask why do we take SIS model for comparing different solution strategy for solving in uncertain environment? Basically we take the particular SIS model and apply the different techniques in uncertain environment. Once one can be familiar with it, anyone can take one of the strategies which best fits their model. 
TABLE 2

\begin{tabular}{lcc}
\hline & $i_{e 1}(t)$ & $i_{e 2}(t)$ \\
\hline$\frac{p_{1}\left(i_{0}\right)}{\partial i_{0}}>0$ & $\frac{i_{01}(\alpha) \cdot p e^{p t}}{i_{01}(\alpha) m\left(e^{p t}-1\right)+p}$ & $\frac{i_{02}(\alpha) p e^{p t}}{i_{02}(\alpha) m\left(e^{p t}-1\right)+p}$ \\
$\frac{\partial p_{1}\left(i_{0}\right)}{\partial i_{0}}<0$ & $\frac{i_{02}(\alpha) p e^{p t}}{i_{02}(\alpha) m\left(e^{p t}-1\right)+p}$ & $\frac{i_{01}(\alpha) p e^{p t}}{i_{01}(\alpha) m\left(e^{p t}-1\right)+p}$ \\
\hline
\end{tabular}

\section{Solution of the above SIS Model in Fuzzy Environment by Different Strategy}

5.1. Solution of Fuzzy SIS Model via Differential Inclusion.

$$
\begin{aligned}
& \left(\frac{d s(t)}{d t}, \frac{d i(t)}{d t}\right) \\
& =(-m s(t) i(t)+\gamma i(t), m s(t) i(t)-\gamma i(t)) \\
& \quad\left(s_{0}, i_{0}\right) \in C .
\end{aligned}
$$

The solution of the problem (30) using differential inclusion is obtained from the solution of the auxiliary

$$
\begin{aligned}
& \left(\frac{d s(t)}{d t}, \frac{d i(t)}{d t}\right) \\
& =(-m s(t) i(t)+\gamma i(t), m s(t) i(t)-\gamma i(t)) \\
& \quad\left(s_{0}, i_{0}\right) \in C(\alpha),
\end{aligned}
$$

where $C(\alpha)=\left\{\left(1-i_{0}, i_{0}\right) \in R^{2}: i_{0}=(1-l) i_{01}(\alpha)+l i_{02}(\alpha), l \in\right.$ $[0,1]\}$.

The attainable sets of the problem of (31) can be written as

$A_{t}(C(\alpha))=\left\{u\left(t, s_{0}, i_{0}\right): u\left(\cdot, s_{0}, i_{0}\right)\right.$, solution of $\left.(31)\right\}=$ $\left\{u\left(t, s_{0}, i_{0}\right): u^{\prime}\left(t, s_{0}, i_{0}\right)=(-m s i+\gamma i, m s i-\gamma i),\left(s_{0}, i_{0}\right) \in C(\alpha)\right\}$.

Case 1 (when $p=m-\gamma \neq 0$ ).

$$
\begin{aligned}
& A_{t}(C(\alpha))=\left\{\left(\frac{i_{0} e^{p t}(m-p)+p-i_{0} m}{i_{0} m\left(e^{p t}-1\right)+p},\right.\right. \\
& \left.\quad \frac{i_{0} p e^{p t}}{i_{0} m\left(e^{p t}-1\right)+p}\right): i_{0}=(1-l) i_{01}(\alpha)+l i_{02}(\alpha), l \\
& \quad \in[0,1]\} .
\end{aligned}
$$

Case $2($ when $p=m-\gamma=0)$.

$$
\begin{gathered}
A_{t}(C(\alpha))=\left\{\left(\frac{1+i_{0}(m t-1)}{1+m t i_{0}}, \frac{i_{0}}{1+m t i_{0}}\right): i_{0}\right. \\
\left.=(1-l) i_{01}(\alpha)+l i_{02}(\alpha), l \in[0,1]\right\} .
\end{gathered}
$$

5.2. Solution of Fuzzy SIS Model by Extension Principle Method. Let $\left[i_{e 1}(t), i_{e 2}(t)\right]$ and $\left[s_{e 1}(t), s_{e 2}(t)\right]$ be the solution by extension principle method.
Now different cases arise.

Case 1 (when $p=m-\gamma \neq 0$ ). In this case the solution can be written as

$$
\begin{aligned}
& i_{e 1}(t) \\
& =\max \left\{\frac{i_{0} p e^{p t}}{i_{0} m\left(e^{p t}-1\right)+p} \mid i_{0} \in\left[i_{01}(\alpha), i_{02}(\alpha)\right]\right\}, \\
& i_{e 2}(t) \\
& \quad=\min \left\{\frac{i_{0} p e^{p t}}{i_{0} m\left(e^{p t}-1\right)+p} \mid i_{0} \in\left[i_{01}(\alpha), i_{02}(\alpha)\right]\right\} .
\end{aligned}
$$

The solution depends on the function $p_{1}\left(i_{0}\right)=i_{0} p e^{p t} /$ $\left(i_{0} m\left(e^{p t}-1\right)+p\right)$ whether it is increasing or decreasing. The solution can be written as in Table 2 .

Here,

$$
\frac{\partial p_{1}\left(i_{0}\right)}{\partial i_{0}}=\frac{i_{0} p e^{p t}}{\left\{i_{01}(\alpha) m\left(e^{p t}-1\right)+p\right\}^{2}} .
$$

So, it depends upon $p$, whether it is negative or positive. If we take $p>0$ then

$$
\begin{aligned}
& i_{e 1}(t)=\frac{i_{01}(\alpha) \cdot p e^{p t}}{i_{01}(\alpha) m\left(e^{p t}-1\right)+p} \\
& i_{e 2}(t)=\frac{i_{02}(\alpha) p e^{p t}}{i_{02}(\alpha) m\left(e^{p t}-1\right)+p}
\end{aligned}
$$

and also

$$
\begin{aligned}
& s_{e 1}(t)=\max \left\{\frac{i_{0} e^{p t}(m-p)+p-i_{0} m}{i_{0} m\left(e^{p t}-1\right)+p} \mid i_{0}\right. \\
& \left.\in\left[i_{01}(\alpha), i_{02}(\alpha)\right]\right\}, \\
& s_{e 2}(t)=\min \left\{\frac{i_{0} e^{p t}(m-p)+p-i_{0} m}{i_{0} m\left(e^{p t}-1\right)+p} \mid i_{0}\right. \\
& \left.\in\left[i_{01}(\alpha), i_{02}(\alpha)\right]\right\} .
\end{aligned}
$$

The solution depends on the function $q_{1}\left(i_{0}\right)=\left(i_{0} e^{p t}(m-\right.$ $\left.p)+p-i_{0} m\right) /\left(i_{0} m\left(e^{p t}-1\right)+p\right)$ whether it is increasing or decreasing. The solution can be written as in Table 3 .

Here,

$$
\frac{\partial q_{1}\left(i_{0}\right)}{\partial i_{0}}=-\frac{p m\left(1+e^{p t}\right)}{\left\{i_{0} m\left(e^{p t}-1\right)+p\right\}^{2}}<0
$$


TABLE 3

\begin{tabular}{lcc}
\hline & $s_{e 1}(t)$ & $s_{e 2}(t)$ \\
\hline$\frac{\partial q_{1}\left(i_{0}\right)}{\partial i_{0}}>0$ & $\frac{i_{01}(\alpha) e^{p t}(m-p)+p-i_{01}(\alpha) m}{i_{01}(\alpha) m\left(e^{p t}-1\right)+p}$ & $\frac{i_{02}(\alpha) e^{p t}(m-p)+p-i_{02}(\alpha) m}{i_{02}(\alpha) m\left(e^{p t}-1\right)+p}$ \\
$\frac{\partial q_{1}\left(i_{0}\right)}{\partial i_{0}}<0$ & $\frac{i_{02}(\alpha) e^{p t}(m-p)+p-i_{02}(\alpha) m}{i_{02}(\alpha) m\left(e^{p t}-1\right)+p}$ & $\frac{i_{01}(\alpha) e^{p t}(m-p)+p-i_{01}(\alpha) m}{i_{01}(\alpha) m\left(e^{p t}-1\right)+p}$ \\
\hline
\end{tabular}

TABle 4

\begin{tabular}{lcc}
\hline & $i_{e 1}(t)$ & $i_{e 2}(t)$ \\
\hline$\frac{\partial p_{2}\left(i_{0}\right)}{\partial i_{0}}>0$ & $\frac{i_{01}(\alpha)}{1+m t i_{01}(\alpha)}$ & $\frac{i_{02}(\alpha)}{1+m t i_{02}(\alpha)}$ \\
$\frac{\partial p_{2}\left(i_{0}\right)}{\partial i_{0}}<0$ & $\frac{i_{02}(\alpha)}{1+m t i_{02}(\alpha)}$ & $\frac{i_{01}(\alpha)}{1+m t i_{01}(\alpha)}$ \\
\hline
\end{tabular}

TABLE 5

\begin{tabular}{lrr}
\hline & $s_{e 1}(t)$ & $s_{e 2}(t)$ \\
\hline$\frac{\partial q_{2}\left(i_{0}\right)}{\partial i_{0}}>0$ & $\frac{1+i_{01}(\alpha)(m t-1)}{1+m t i_{01}(\alpha)}$ & $\frac{1+i_{02}(\alpha)(m t-1)}{1+m t i_{02}(\alpha)}$ \\
$\frac{\partial q_{2}\left(i_{0}\right)}{\partial i_{0}}<0$ & $\frac{1+i_{02}(\alpha)(m t-1)}{1+m t i_{02}(\alpha)}$ & $\frac{1+i_{01}(\alpha)(m t-1)}{1+m t i_{01}(\alpha)}$ \\
\hline
\end{tabular}

So, the solution is given by

$$
\begin{aligned}
& s_{e 1}(t)=\frac{i_{02}(\alpha) e^{p t}(m-p)+p-i_{02}(\alpha) m}{i_{02}(\alpha) m\left(e^{p t}-1\right)+p}, \\
& s_{e 2}(t)=\frac{i_{01}(\alpha) e^{p t}(m-p)+p-i_{01}(\alpha) m}{i_{01}(\alpha) m\left(e^{p t}-1\right)+p} .
\end{aligned}
$$

Case 2 (when $p=m-\gamma=0$ ). In this case the solution can be written as

$$
\begin{aligned}
& i_{e 1}(t)=\max \left\{\frac{i_{0}}{1+m t i_{0}} \mid i_{0} \in\left[i_{01}(\alpha), i_{02}(\alpha)\right]\right\}, \\
& i_{e 2}(t)=\min \left\{\frac{i_{0}}{1+m t i_{0}} \mid i_{0} \in\left[i_{01}(\alpha), i_{02}(\alpha)\right]\right\} .
\end{aligned}
$$

The solution depends on the function $p_{2}\left(i_{0}\right)=i_{0} /\left(1+m t i_{0}\right)$ whether it is increasing or decreasing. The solution can be written as in Table 4.

Here,

$$
\frac{\partial p_{2}\left(i_{0}\right)}{\partial i_{0}}=\frac{1}{\left\{1+m t i_{01}(\alpha)\right\}^{2}}>0
$$

Hence the solution is

$$
\begin{aligned}
& i_{e 1}(t)=\frac{i_{01}(\alpha)}{1+m t i_{01}(\alpha)} \\
& i_{e 2}(t)=\frac{i_{02}(\alpha)}{1+m t i_{02}(\alpha)}
\end{aligned}
$$

and also

$$
\begin{aligned}
& s_{e 1}(t) \\
& =\max \left\{\frac{1+i_{0}(m t-1)}{1+m t i_{0}} \mid i_{0} \in\left[i_{01}(\alpha), i_{02}(\alpha)\right]\right\}, \\
& s_{e 2}(t) \\
& =\min \left\{\frac{1+i_{0}(m t-1)}{1+m t i_{0}} \mid i_{0} \in\left[i_{01}(\alpha), i_{02}(\alpha)\right]\right\} .
\end{aligned}
$$

The solution depends on the function $q_{2}\left(i_{0}\right)=\left(1+i_{0}(m t-\right.$ $1)) /\left(1+m t i_{0}\right)$ whether it is increasing or decreasing. The solution can be written as in Table 5 .

Here,

$$
\frac{\partial q_{2}\left(i_{0}\right)}{\partial i_{0}}=-\frac{1}{\left\{1+m t i_{0}\right\}^{2}}<0
$$

Hence the solution is

$$
\begin{aligned}
& s_{e 1}(t)=\frac{1+i_{02}(\alpha)(m t-1)}{1+m t i_{02}(\alpha)}, \\
& s_{e 2}(t)=\frac{1+i_{01}(\alpha)(m t-1)}{1+m t i_{01}(\alpha)} .
\end{aligned}
$$

5.3. Solution of Fuzzy SIS Model by Fuzzy Differential Equation Approach. Let $\left[i_{1}(t, \alpha), i_{2}(t, \alpha)\right]$ and $\left[s_{1}(t, \alpha), s_{2}(t, \alpha)\right]$ be the solution using generalized Hukuhara derivative approach. 
Now different cases can be found as follows.

Case $1(s(t)$ and $i(t)$ is (i)-gH differentiable). In this case the differential equation transforms to

$$
\begin{aligned}
& \frac{d s_{1}(t, \alpha)}{d t}=-m s_{2}(t, \alpha) i_{2}(t, \alpha)+\gamma i_{1}(t, \alpha) \\
& \frac{d s_{2}(t, \alpha)}{d t}=-m s_{1}(t, \alpha) i_{1}(t, \alpha)+\gamma i_{2}(t, \alpha) \\
& \frac{d i_{1}(t, \alpha)}{d t}=m s_{1}(t, \alpha) i_{1}(t, \alpha)-\gamma i_{2}(t, \alpha) \\
& \frac{d i_{2}(t, \alpha)}{d t}=m s_{2}(t, \alpha) i_{2}(t, \alpha)-\gamma i_{1}(t, \alpha),
\end{aligned}
$$

with initial conditions $s_{1}(0, \alpha)=s_{01}(\alpha), s_{2}(0, \alpha)=s_{02}(\alpha)$, $i_{1}(0, \alpha)=i_{01}(\alpha)$, and $i_{2}(0, \alpha)=i_{02}(\alpha)$.

Case $2(s(t)$ is (i)-gH and $i(t)$ is (ii)-gH differentiable). In this case the differential equation transforms to

$$
\begin{aligned}
& \frac{d s_{1}(t, \alpha)}{d t}=-m s_{2}(t, \alpha) i_{2}(t, \alpha)+\gamma i_{1}(t, \alpha) \\
& \frac{d s_{2}(t, \alpha)}{d t}=-m s_{1}(t, \alpha) i_{1}(t, \alpha)+\gamma i_{2}(t, \alpha) \\
& \frac{d i_{2}(t, \alpha)}{d t}=m s_{1}(t, \alpha) i_{1}(t, \alpha)-\gamma i_{2}(t, \alpha) \\
& \frac{d i_{1}(t, \alpha)}{d t}=m s_{2}(t, \alpha) i_{2}(t, \alpha)-\gamma i_{1}(t, \alpha),
\end{aligned}
$$

with initial conditions $s_{1}(0, \alpha)=s_{01}(\alpha), s_{2}(0, \alpha)=s_{02}(\alpha)$, $i_{1}(0, \alpha)=i_{01}(\alpha)$, and $i_{2}(0, \alpha)=i_{02}(\alpha)$.

Case $3(s(t)$ is (ii)-gH and $i(t)$ is (i)-gH differentiable). In this case the differential equation transforms to

$$
\begin{aligned}
& \frac{d s_{2}(t, \alpha)}{d t}=-m s_{2}(t, \alpha) i_{2}(t, \alpha)+\gamma i_{1}(t, \alpha) \\
& \frac{d s_{1}(t, \alpha)}{d t}=-m s_{1}(t, \alpha) i_{1}(t, \alpha)+\gamma i_{2}(t, \alpha) \\
& \frac{d i_{1}(t, \alpha)}{d t}=m s_{1}(t, \alpha) i_{1}(t, \alpha)-\gamma i_{2}(t, \alpha) \\
& \frac{d i_{2}(t, \alpha)}{d t}=m s_{2}(t, \alpha) i_{2}(t, \alpha)-\gamma i_{1}(t, \alpha),
\end{aligned}
$$

with initial conditions $s_{1}(0, \alpha)=s_{01}(\alpha), s_{2}(0, \alpha)=s_{02}(\alpha)$, $i_{1}(0, \alpha)=i_{01}(\alpha)$, and $i_{2}(0, \alpha)=i_{02}(\alpha)$.

Case $4(s(t)$ and $i(t)$ is (ii)-gH differentiable). In this case the differential equation transforms to

$$
\begin{aligned}
& \frac{d s_{2}(t, \alpha)}{d t}=-m s_{2}(t, \alpha) i_{2}(t, \alpha)+\gamma i_{1}(t, \alpha) \\
& \frac{d s_{1}(t, \alpha)}{d t}=-m s_{1}(t, \alpha) i_{1}(t, \alpha)+\gamma i_{2}(t, \alpha) \\
& \frac{d i_{2}(t, \alpha)}{d t}=m s_{1}(t, \alpha) i_{1}(t, \alpha)-\gamma i_{2}(t, \alpha) \\
& \frac{d i_{1}(t, \alpha)}{d t}=m s_{2}(t, \alpha) i_{2}(t, \alpha)-\gamma i_{1}(t, \alpha),
\end{aligned}
$$

with initial condition $s_{1}(0, \alpha)=s_{01}(\alpha), s_{2}(0, \alpha)=s_{02}(\alpha)$, $i_{1}(0, \alpha)=i_{01}(\alpha)$, and $i_{2}(0, \alpha)=i_{02}(\alpha)$

\section{Modeling SIS in Interval Environment}

The problem in interval environment is

$$
\begin{aligned}
& \frac{d s(t, \lambda)}{d t}=-m s(t ; \lambda) i(t ; \lambda)+\gamma i(t ; \lambda) \\
& \frac{d i(t, \lambda)}{d t}=m s(t ; \lambda) i(t ; \lambda)-\gamma i(t ; \lambda),
\end{aligned}
$$

where $m=\beta N(t)$ with initial condition $i(0 ; \lambda)=\left(i_{0 l}\right)^{1-\lambda}\left(i_{0 u}\right)^{\lambda}$ at $t=0, s(t)+i(t)=1$.

We get the solution for two cases as follows.

Case 1 (when $p \neq 0$ ). The solution is written as

$$
\begin{aligned}
& i(t ; \lambda)=\frac{\left(i_{0 u}\right)^{1-\lambda}\left(i_{0 v}\right)^{\lambda} p e^{p t}}{\left(i_{0 u}\right)^{1-\lambda}\left(i_{0 v}\right)^{\lambda} m\left(e^{p t}-1\right)+p}, \\
& s(t ; \lambda)=1-\frac{\left(i_{0 u}\right)^{1-\lambda}\left(i_{0 v}\right)^{\lambda} p e^{p t}}{\left(i_{0 u}\right)^{1-\lambda}\left(i_{0 v}\right)^{\lambda} m\left(e^{p t}-1\right)+p} .
\end{aligned}
$$

Case 2 (when $p=0$ ). The solution is written as

$$
\begin{aligned}
& i(t, \lambda)=\frac{\left(i_{0 u}\right)^{1-\lambda}\left(i_{0 v}\right)^{\lambda}}{1+m t\left(i_{0 u}\right)^{1-\lambda}\left(i_{0 v}\right)^{\lambda}}, \\
& s(t ; \lambda)=1-\frac{\left(i_{0 u}\right)^{1-\lambda}\left(i_{0 v}\right)^{\lambda}}{1+m t\left(i_{0 u}\right)^{1-\lambda}\left(i_{0 v}\right)^{\lambda}} .
\end{aligned}
$$

\section{Numerical Examples}

7.1. Numerical Example on Fuzzy Cases. Find the solution after $t=10$ when $\widetilde{S}_{0}=(0.80,0.85,0.90,0.95)$ and $\widetilde{I}_{0}=$ $(0.05,0.10,0.15,0.20)$, when $m=0.3$ and $\gamma=0.005$.

Solution by differential inclusion and extension principle and fuzzy differential equation is given by

$$
\begin{gathered}
{\left[\left(s_{i 1}(t, \alpha), s_{i 2}(t, \alpha)\right) ;\left(i_{i 1}(t, \alpha), i_{i 2}(t, \alpha)\right)\right],} \\
{\left[\left(s_{e 1}(t, \alpha), s_{e 2}(t, \alpha)\right) ;\left(i_{e 1}(t, \alpha), i_{e 2}(t, \alpha)\right)\right],} \\
{\left[\left(s_{1}(t, \alpha), s_{2}(t, \alpha)\right) ;\left(i_{1}(t, \alpha), i_{2}(t, \alpha)\right)\right] .}
\end{gathered}
$$

\subsubsection{Solution by Differential Inclusion.}

Case 1 (when $p \neq 0$ ).

$$
\begin{aligned}
& A_{t}(C(\alpha))=\left\{\left(\frac{0.005 i_{0} e^{0.295 t}+0.295-0.305 i_{0}}{0.3 i_{0}\left(e^{0.295 t}-1\right)+0.295},\right.\right. \\
& \left.\frac{0.295 i_{0} e^{0.295 t}}{0.3 i_{0}\left(e^{0.295 t}-1\right)+0.295}\right): i_{0}=(1-l)(0.05 \\
& +0.05 \alpha)+l(0.20-0.05 \alpha), l \in[0,1]\} .
\end{aligned}
$$


TABLE 6: Solution boundary for $t=10$.

\begin{tabular}{lcccc}
\hline$\alpha$ & $s_{i 1}(t, \alpha)$ & $s_{i 2}(t, \alpha)$ & $i_{i 1}(t, \alpha)$ & $i_{i 2}(t, \alpha)$ \\
\hline 0 & 0.5022 & 0.1832 & 0.4974 & 0.8160 \\
0.2 & 0.4549 & 0.1923 & 0.5446 & 0.8070 \\
0.4 & 0.4152 & 0.2022 & 0.5843 & 0.7971 \\
0.6 & 0.3814 & 0.2129 & 0.6181 & 0.7864 \\
0.8 & 0.3523 & 0.2246 & 0.6471 & 0.7747 \\
1 & 0.3270 & 0.2375 & 0.6724 & 0.7618 \\
\hline
\end{tabular}

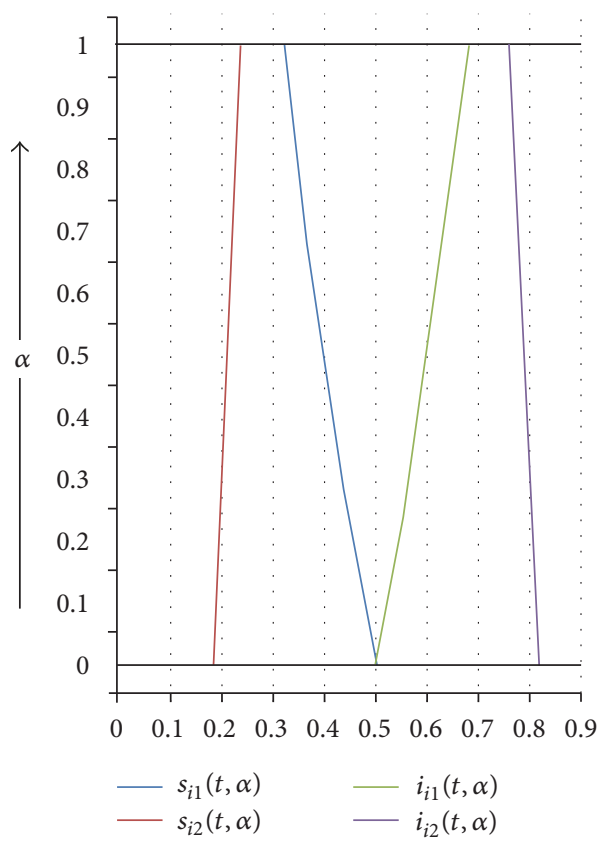

FIGURE 1: Solution boundary for $t=10$.

The boundary of the solution is given by

$$
\begin{aligned}
& s_{i 1}(t, \alpha) \\
& =\frac{0.005(0.05+0.05 \alpha) e^{0.295 t}+0.295-0.305(0.05+0.05 \alpha)}{0.3(0.05+0.05 \alpha)\left(e^{0.295 t}-1\right)+0.295} \\
& s_{i 2}(t, \alpha) \\
& =\frac{0.005(0.20-0.05 \alpha) e^{0.295 t}+0.295-0.305(0.20-0.05 \alpha)}{0.3(0.20-0.05 \alpha)\left(e^{0.295 t}-1\right)+0.295} \\
& i_{i 1}(t, \alpha)=\frac{0.295(0.05+0.05 \alpha) e^{0.295 t}}{0.3(0.05+0.05 \alpha)\left(e^{0.295 t}-1\right)+0.295} \\
& i_{i 2}(t, \alpha)=\frac{0.295(0.20-0.05 \alpha) e^{0.295 t}}{0.3(0.20-0.05 \alpha)\left(e^{0.295 t}-1\right)+0.295} .
\end{aligned}
$$

Remarks 21. From Figure 1 and Table 6 it shows that $s_{i 1}(t, \alpha)$ is decreasing and $s_{i 2}(t, \alpha)$ is increasingwhereas $i_{i 1}(t, \alpha)$ is increasing and $i_{i 2}(t, \alpha)$ is decreasing. The figure demonstrates the boundary of the solution. The solution for $\widetilde{s}(t)$ gives the natural weak solution but $i(t)$ gives the natural strong solution.

Case 2 (when $p=0$ ). The boundary of the solutions is

$$
\begin{aligned}
& A_{t}(C(\alpha))=\left\{\left(\frac{1+i_{0}(0.3 t-1)}{1+0.3 t i_{0}}, \frac{i_{0}}{1+0.3 t i_{0}}\right): i_{0}\right. \\
& \quad=(1-l)(0.05+0.05 \alpha)+l(0.20-0.05 \alpha), l \\
& \quad \in[0,1]\} .
\end{aligned}
$$

Remarks 22. From Figure 2 and Table 7 it shows that $s_{i 1}(t, \alpha)$ is decreasing and $s_{i 2}(t, \alpha)$ is increasing whereas $i_{i 1}(t, \alpha)$ is increasing and $i_{i 2}(t, \alpha)$ is decreasing. The figure demonstrates the boundary of the solution. The solution for $\widetilde{s}(t)$ gives the natural weak solution but $i(t)$ gives the natural strong solution.

\subsection{Solution by Extension Principle.}

Case 1 (when $p \neq 0$ ). Here the solutions are given by

$$
\begin{aligned}
& s_{i 1}(t, \alpha) \\
& =\frac{0.005(0.20-0.05 \alpha) e^{0.295 t}+0.295-0.305(0.20-0.05 \alpha)}{0.3(0.20-0.05 \alpha)\left(e^{0.295 t}-1\right)+0.295} \\
& s_{i 2}(t, \alpha) \\
& =\frac{0.005(0.05+0.05 \alpha) e^{0.295 t}+0.295-0.305(0.05+0.05 \alpha)}{0.3(0.05+0.05 \alpha)\left(e^{0.295 t}-1\right)+0.295} \\
& i_{i 1}(t, \alpha)=\frac{0.295(0.05+0.05 \alpha) e^{0.295 t}}{0.3(0.05+0.05 \alpha)\left(e^{0.295 t}-1\right)+0.295} \\
& i_{i 2}(t, \alpha)=\frac{0.295(0.20-0.05 \alpha) e^{0.295 t}}{0.3(0.20-0.05 \alpha)\left(e^{0.295 t}-1\right)+0.295} .
\end{aligned}
$$

Remarks 23. From Figure 3 and Table 8 it shows that $s_{i 1}(t, \alpha)$ is increasing and $s_{i 2}(t, \alpha)$ is decreasing whereas $i_{i 1}(t, \alpha)$ is increasing and $i_{i 2}(t, \alpha)$ is decreasing. The figure demonstrates the solution of the problem. The solution for $\widetilde{s}(t)$ gives the natural strong solution but $i(t)$ gives the natural strong solution. 
TABLE 7: Solutions boundary for $t=10$.

\begin{tabular}{lllll}
\hline$\alpha$ & $s_{i 1}(t, \alpha)$ & $s_{i 2}(t, \alpha)$ & $i_{i 1}(t, \alpha)$ & $i_{i 2}(t, \alpha)$ \\
\hline 0 & 0.9565 & 0.8750 & 0.0435 & 0.1250 \\
0.2 & 0.9492 & 0.8790 & 0.0508 & 0.1210 \\
0.4 & 0.9421 & 0.8831 & 0.0579 & 0.1169 \\
0.6 & 0.9355 & 0.8874 & 0.0645 & 0.1126 \\
0.8 & 0.9291 & 0.8919 & 0.0709 & 0.1081 \\
1 & 0.9231 & 0.8966 & 0.0769 & 0.1034 \\
\hline
\end{tabular}

TABLE 8: Solution for $t=10$.

\begin{tabular}{lcccc}
\hline$\alpha$ & $s_{e 1}(t, \alpha)$ & $s_{e 2}(t, \alpha)$ & $i_{e 1}(t, \alpha)$ & $i_{e 2}(t, \alpha)$ \\
\hline 0 & 0.1832 & 0.5022 & 0.4974 & 0.8160 \\
0.2 & 0.1923 & 0.4549 & 0.5446 & 0.8070 \\
0.4 & 0.2022 & 0.4152 & 0.5843 & 0.7971 \\
0.6 & 0.2129 & 0.3814 & 0.6181 & 0.7864 \\
0.8 & 0.2246 & 0.3523 & 0.6471 & 0.7747 \\
1 & 0.2375 & 0.3270 & 0.6724 & 0.7618 \\
\hline
\end{tabular}

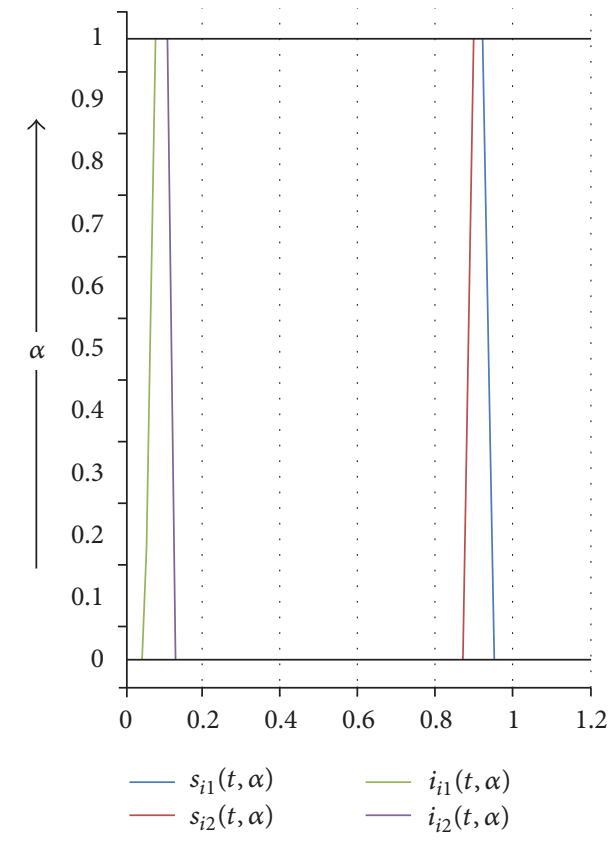

Figure 2: Solutions boundary for $t=10$.

Case 2 (when $p=0$ ). The solutions are given by

$$
\begin{aligned}
& s_{i 1}(t, \alpha)=\frac{1+(0.20-0.05 \alpha)(0.3 t-1)}{1+0.3 t(0.20-0.05 \alpha)} \\
& s_{i 2}(t, \alpha)=\frac{1+(0.05+0.05 \alpha)(0.3 t-1)}{1+0.3 t(0.05+0.05 \alpha)} \\
& i_{i 1}(t, \alpha)=\frac{(0.05+0.05 \alpha)}{1+0.3 t(0.05+0.05 \alpha)} \\
& i_{i 2}(t, \alpha)=\frac{(0.20-0.05 \alpha)}{1+0.3 t(0.20-0.05 \alpha)} .
\end{aligned}
$$

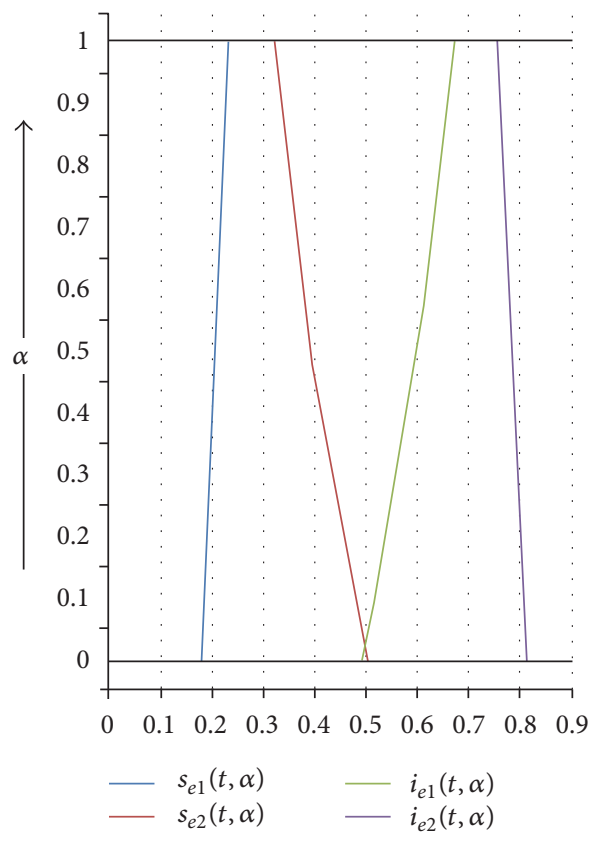

FIGURE 3: Solution for $t=10$.

Remarks 24. From Figure 4 and Table 9 it shows that $s_{i 1}(t, \alpha)$ is increasing and $s_{i 2}(t, \alpha)$ is decreasing whereas $i_{i 1}(t, \alpha)$ is increasing and $i_{i 2}(t, \alpha)$ is decreasing. The figure demonstrates the solution of the problem. The solution for $\widetilde{s}(t)$ gives the natural strong solution and $i(t)$ gives the natural strong solution.

7.3. Solution by Fuzzy Differential Equation Approach. Now the solutions for different cases are given by the following.

Case $1(s(t)$ and $i(t)$ is (i)-gH differentiable).

Remarks 25. From Figure 5 and Table 10 it shows that $s_{i 1}(t, \alpha)$ is increasing and $s_{i 2}(t, \alpha)$ is decreasing whereas $i_{i 1}(t, \alpha)$ is 
TABLE 9: Solution for $t=10$.

\begin{tabular}{lcccc}
\hline$\alpha$ & $s_{e 1}(t, \alpha)$ & $s_{e 2}(t, \alpha)$ & $i_{e 1}(t, \alpha)$ & $i_{e 2}(t, \alpha)$ \\
\hline 0 & 0.8750 & 0.9565 & 0.0435 & 0.1250 \\
0.2 & 0.8790 & 0.9492 & 0.0508 & 0.1210 \\
0.4 & 0.8831 & 0.9421 & 0.0579 & 0.1169 \\
0.6 & 0.8874 & 0.9355 & 0.0645 & 0.1126 \\
0.8 & 0.8919 & 0.9291 & 0.0709 & 0.1081 \\
1 & 0.8966 & 0.9231 & 0.0769 & 0.1034 \\
\hline
\end{tabular}

TABLE 10: Solutions for $t=10$.

\begin{tabular}{lcccc}
\hline$\alpha$ & $s_{1}(t, \alpha)$ & $s_{2}(t, \alpha)$ & $i_{1}(t, \alpha)$ & $i_{2}(t, \alpha)$ \\
\hline 0 & 0.4471 & 0.9046 & 0.0954 & 0.5529 \\
0.2 & 0.4845 & 0.8810 & 0.1190 & 0.5155 \\
0.4 & 0.5209 & 0.8564 & 0.1436 & 0.4791 \\
0.6 & 0.5564 & 0.8308 & 0.1692 & 0.4436 \\
0.8 & 0.5908 & 0.8043 & 0.1957 & 0.4092 \\
1 & 0.6243 & 0.7768 & 0.2232 & 0.3757 \\
\hline
\end{tabular}

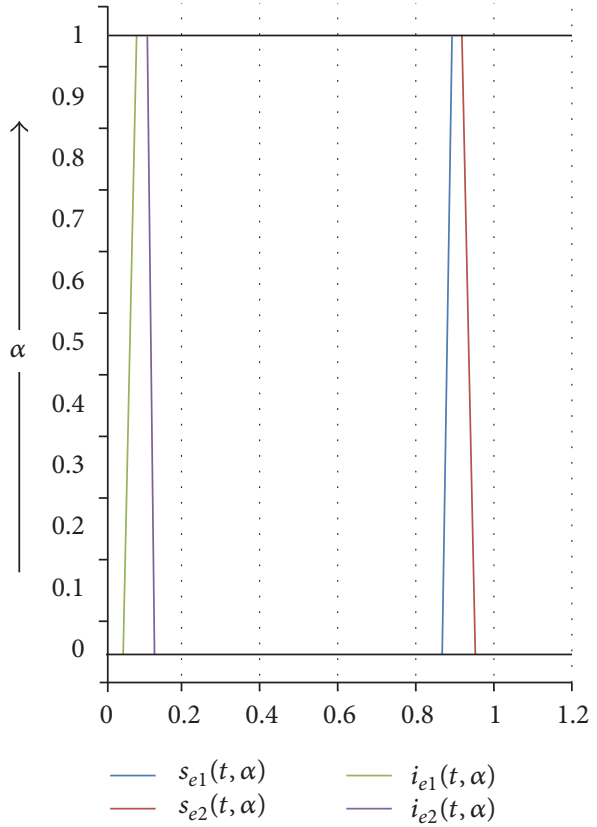

FIGURE 4: Solution for $t=10$.

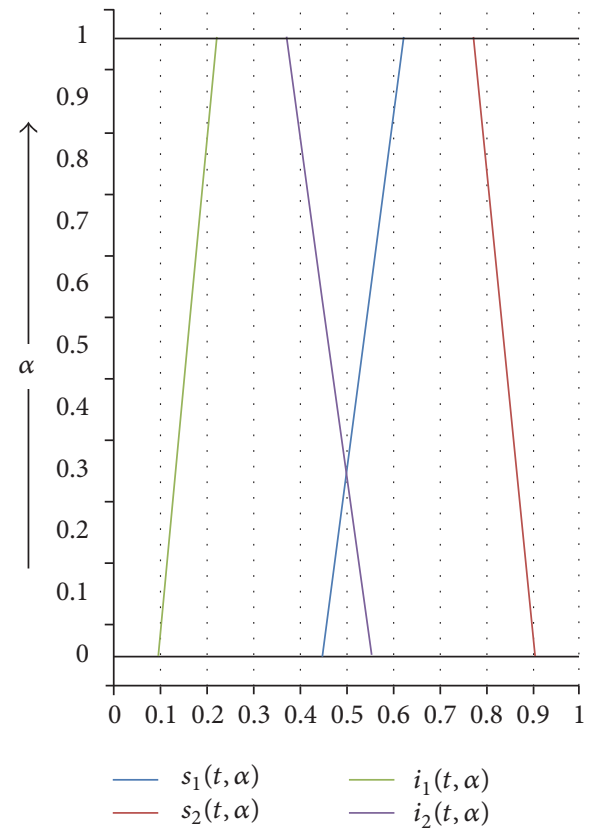

FIGURE 5: Figure for $t=10$. increasing and $i_{i 2}(t, \alpha)$ is decreasing. The figure demonstrates the solution of the problem. The solution for $\widetilde{s}(t)$ gives the natural strong solution and $\widetilde{i}(t)$ gives the natural strong solution.

Case $2(s(t)$ is (i)-gH and $i(t)$ is (ii)-gH differentiable).

Remarks 26. From Figure 6 and Table 11 it shows that $s_{i 1}(t, \alpha)$ is increasing and $s_{i 2}(t, \alpha)$ is decreasing whereas $i_{i 1}(t, \alpha)$ is increasing and $i_{i 2}(t, \alpha)$ is decreasing. The figure demonstrates the solution of the problem. The solution for $\widetilde{s}(t)$ gives the natural weak solution but $\widetilde{i}(t)$ gives the natural strong solution.

Case $3(s(t)$ is (ii)-gH and $i(t)$ is (i)-gH differentiable).

Remarks 27. From Figure 7 and Table 12 it shows that $s_{i 1}(t, \alpha)$ is increasing and $s_{i 2}(t, \alpha)$ is decreasing whereas $i_{i 1}(t, \alpha)$ is increasing and $i_{i 2}(t, \alpha)$ is decreasing. The figure demonstrates the solution of the problem. The solution for $\widetilde{s}(t)$ gives the natural weak solution but $\widetilde{i}(t)$ gives the natural strong solution. 
TABLE 11: Solution for $t=10$.

\begin{tabular}{lcccc}
\hline$\alpha$ & $s_{1}(t, \alpha)$ & $s_{2}(t, \alpha)$ & $i_{1}(t, \alpha)$ & $i_{2}(t, \alpha)$ \\
\hline 0 & 0.7403 & 0.6601 & 0.1097 & 0.4899 \\
0.2 & 0.7359 & 0.6662 & 0.1341 & 0.4638 \\
0.4 & 0.7313 & 0.6722 & 0.1587 & 0.4378 \\
0.6 & 0.7266 & 0.6782 & 0.1834 & 0.4118 \\
0.8 & 0.7218 & 0.6840 & 0.2082 & 0.3860 \\
1 & 0.7168 & 0.6898 & 0.2332 & 0.3602 \\
\hline
\end{tabular}

TABLE 12: Solution for $t=10$.

\begin{tabular}{lcccc}
\hline$\alpha$ & $s_{1}(t, \alpha)$ & $s_{2}(t, \alpha)$ & $i_{1}(t, \alpha)$ & $i_{2}(t, \alpha)$ \\
\hline 0 & 0.7403 & 0.6601 & 0.1097 & 0.4899 \\
0.2 & 0.7359 & 0.6662 & 0.1341 & 0.4638 \\
0.4 & 0.7313 & 0.6722 & 0.1587 & 0.4378 \\
0.6 & 0.7266 & 0.6782 & 0.1834 & 0.4118 \\
0.8 & 0.7218 & 0.6840 & 0.2082 & 0.3860 \\
1 & 0.7168 & 0.6898 & 0.2332 & 0.3602 \\
\hline
\end{tabular}

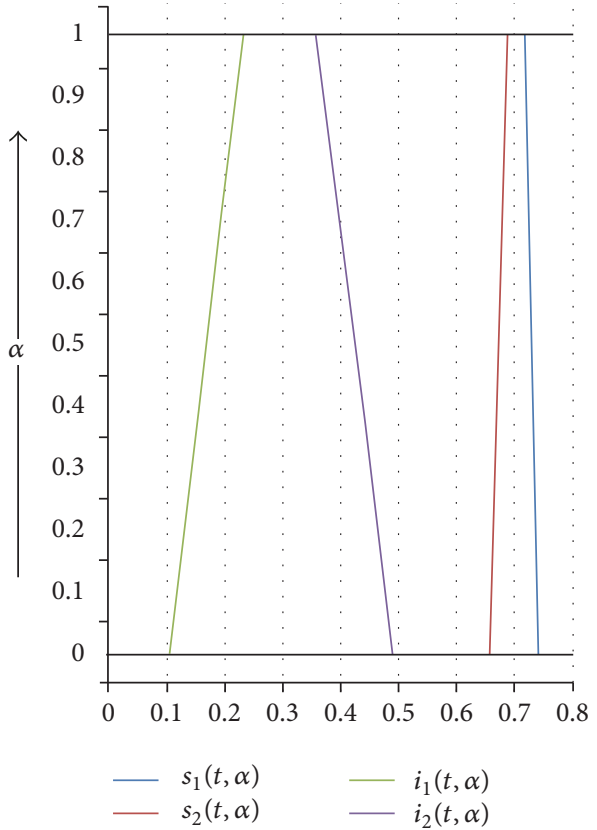

FIGURE 6: Figure for $t=10$.

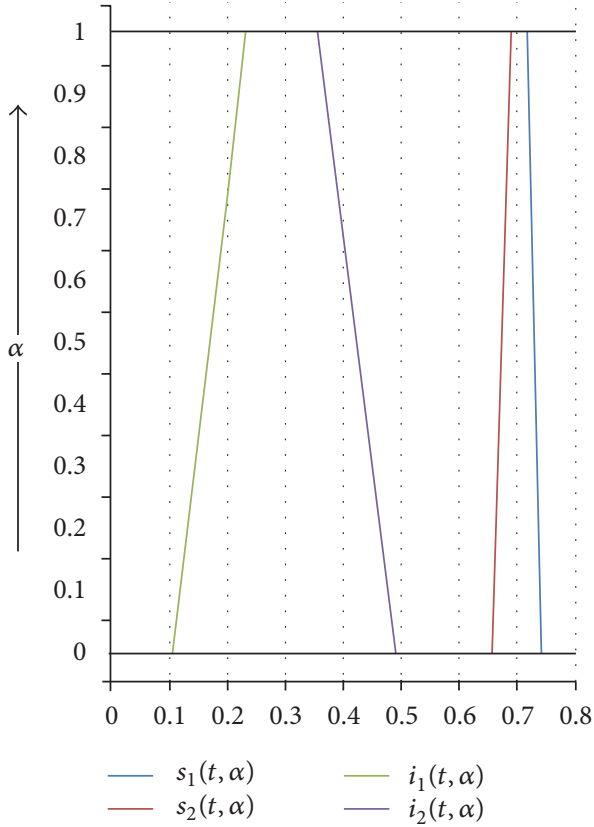

FIGURE 7: Solution for $t=10$.

Case $4(s(t)$ and $i(t)$ is (ii)-gH differentiable).

Remarks 28. From Figure 8 and Table 13 it shows that $s_{i 1}(t, \alpha)$ Case 1 (when $p \neq 0)$. is increasing and $s_{i 2}(t, \alpha)$ is decreasing whereas $i_{i 1}(t, \alpha)$ is increasing and $i_{i 2}(t, \alpha)$ is decreasing. The figure demonstrates the solution of the problem. The solution for $\widetilde{s}(t)$ gives the natural strong solution and $i(t)$ gives the natural strong solution.

7.4. Numerical Example on Interval Cases. Find the solution after $t=10$ when $\widehat{S}=[0.80,0.95]$ and $\widehat{I}=[0.05,0.20]$, when $m=0.3$ and $\gamma=0.005$.

$s(t ; \lambda)=1$

$$
-\frac{0.295(0.05)^{1-\lambda}(0.20)^{\lambda} e^{0.295 t}}{0.3(0.05)^{1-\lambda}(0.20)^{\lambda}\left(e^{0.295 t}-1\right)+0.295},
$$

$$
i(t ; \lambda)=\frac{0.295(0.05)^{1-\lambda}(0.20)^{\lambda} e^{0.295 t}}{0.3(0.05)^{1-\lambda}(0.20)^{\lambda}\left(e^{0.295 t}-1\right)+0.295} .
$$


TABLE 13: Solution for $t=10$.

\begin{tabular}{lcccc}
\hline$\alpha$ & $s_{1}(t, \alpha)$ & $s_{2}(t, \alpha)$ & $i_{1}(t, \alpha)$ & $i_{2}(t, \alpha)$ \\
\hline 0 & 0.6855 & 0.7376 & 0.2624 & 0.3145 \\
0.2 & 0.6872 & 0.7317 & 0.2683 & 0.3128 \\
0.4 & 0.6883 & 0.7254 & 0.2746 & 0.3117 \\
0.6 & 0.6875 & 0.7171 & 0.2829 & 0.3125 \\
0.8 & 0.6914 & 0.7143 & 0.2857 & 0.3086 \\
1 & 0.6950 & 0.7114 & 0.2886 & 0.3050 \\
\hline
\end{tabular}

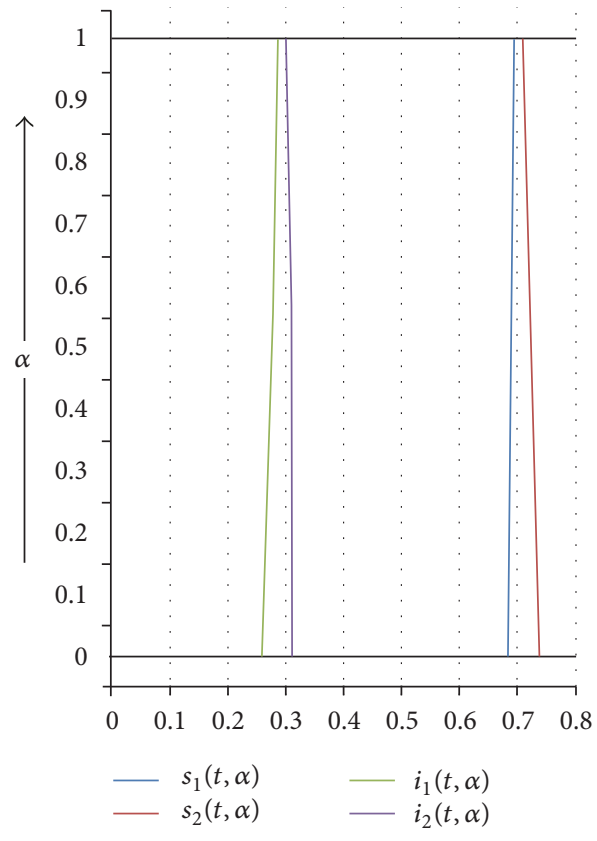

FIGURE 8: Figure for $t=10$.

Case $2($ when $p=0)$.

$$
\begin{aligned}
& s(t ; \lambda)=1-\frac{(0.05)^{1-\lambda}(0.20)^{\lambda}}{1+0.3 t(0.05)^{1-\lambda}(0.20)^{\lambda}}, \\
& i(t, \lambda)=\frac{(0.05)^{1-\lambda}(0.20)^{\lambda}}{1+0.3 t(0.05)^{1-\lambda}(0.20)^{\lambda}} .
\end{aligned}
$$

Remarks 29. From Figures 9 and 10 and Tables 14 and 15 it shows that $s_{i 1}(t, \alpha)$ is increasing and $s_{i 2}(t, \alpha)$ is decreasing whereas $i_{i 1}(t, \alpha)$ is increasing and $i_{i 2}(t, \alpha)$ is decreasing. The figure demonstrates the solution of the problem. The solution for $\widetilde{s}(t)$ gives the natural strong solution but $i(t)$ gives the natural strong solution.

\section{Conclusion}

In this paper we study the different solution strategies for analyzing fuzzy differential equation and application in mathematical biology model, namely, SIS model, which is
TABLE 14: Solution for $t=10$.

\begin{tabular}{lll}
\hline$\lambda$ & $s(t ; \lambda)$ & $i(t ; \lambda)$ \\
\hline 0 & 0.5026 & 0.4974 \\
0.2 & 0.4309 & 0.5691 \\
0.4 & 0.3610 & 0.6390 \\
0.6 & 0.2955 & 0.7045 \\
0.8 & 0.2361 & 0.7639 \\
1 & 0.1840 & 0.8160 \\
\hline
\end{tabular}

TABLE 15: Solution at $t=10$.

\begin{tabular}{lll}
\hline$\lambda$ & $s(t ; \lambda)$ & $i(t, \lambda)$ \\
\hline 0 & 0.9565 & 0.0435 \\
0.2 & 0.9449 & 0.0551 \\
0.4 & 0.9310 & 0.0690 \\
0.6 & 0.9146 & 0.0854 \\
0.8 & 0.8958 & 0.1042 \\
1 & 0.8750 & 0.1250 \\
\hline
\end{tabular}

considered to be an important area of research in biological research. The approaches regarding fuzzy differential inclusion, extension principle, and fuzzy differential equation were applied to find the fuzzy solutions of the given model. The whole paper is concluded as follows:

(i) Demonstrating SIS model with fuzzy numbers which enabled meeting the uncertain parameters as well, which is appreciatively helpful for the decision makers to investigate the situation in a more precise manner.

(ii) The different approaches having significant place in fuzzy calculus efficiently made it possible to obtain the fuzzy solution of the governing model by different methods.

(iii) The use of correlated fuzzy number in the said model is for finding the fuzzy solution.

Thus in the future we seek to apply these concepts to different types of differential equation models in fuzzy environments. 


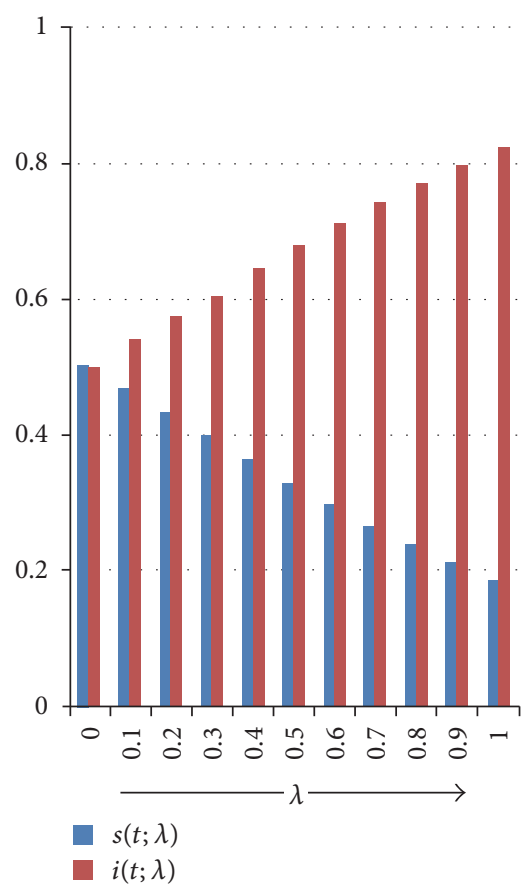

Figure 9: Figure at $t=10$.

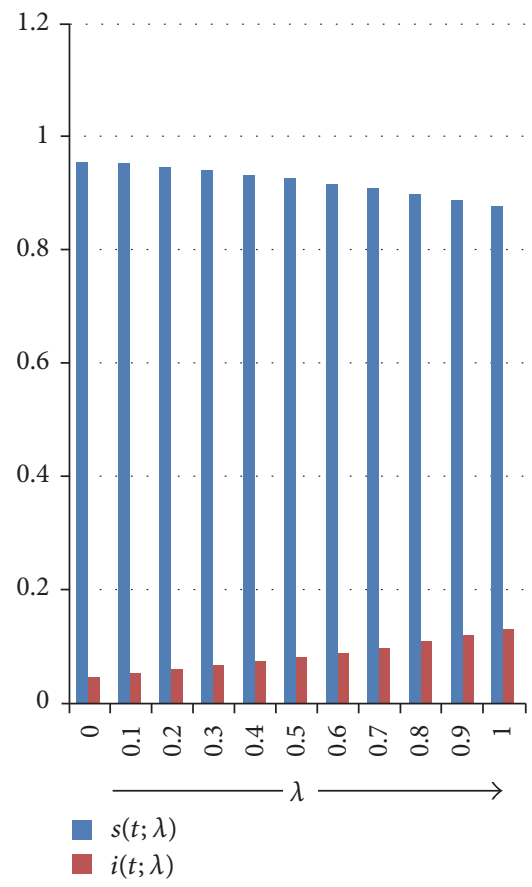

FIGURE 10: Figure at $t=10$.

\section{Conflicts of Interest}

The authors declare that they have no conflicts of interest.

\section{Acknowledgments}

The second author of the article wishes to convey his heartiest thanks to Miss. Gullu for inspiring him to write the article.

\section{References}

[1] L. A. Zadeh, "Fuzzy sets," Information and Control, vol. 8, no. 3, pp. 338-353, 1965.

[2] S. S. L. Chang and L. A. Zadeh, "On Fuzzy Mapping and Control," IEEE Transactions on Systems, Man, and Cybernetics, vol. 2, no. 1, pp. 30-34, 1972.

[3] D. Qiu, W. Zhang, and C. Lu, "On fuzzy differential equations in the quotient space of fuzzy numbers," Fuzzy Sets and Systems, vol. 295, pp. 72-98, 2016.

[4] D. Qiu, C. Lu, W. Zhang, and Y. Lan, "Algebraic properties and topological properties of the quotient space of fuzzy numbers based on Mareš equivalence relation," Fuzzy Sets and Systems, vol. 245, pp. 63-82, 2014.

[5] D. Qiu and W. Zhang, "Symmetric fuzzy numbers and additive equivalence of fuzzy numbers," Soft Computing, vol. 17, no. 8, pp. 1471-1477, 2013.

[6] S. Abbasbandy and B. Asady, "Newton's method for solving fuzzy nonlinear equations," Applied Mathematics and Computation, vol. 159, no. 2, pp. 349-356, 2004.

[7] J. J. Buckley, T. Feuring, and Y. Hayashi, "Linear systems of first order ordinary differential equations: fuzzy initial conditions," Soft Computing, vol. 6, no. 6, pp. 415-421, 2002.

[8] O. Abu Arqub, "Adaptation of reproducing kernel algorithm for solving fuzzy Fredholm-Volterra integro differential equations," Neural Computing \& Applications, pp. 1-20, 2015.

[9] O. Abu Arqub, S. Momani, S. Al-Mezel, and M. Kutbi, "Existence, uniqueness, and characterization theorems for nonlinear fuzzy integrodifferential equations of Volterra type," Mathematical Problems in Engineering, vol. 2015, Article ID 835891, 13 pages, 2015.

[10] S. Momani, O. Abu Arqub, S. Al-Mezel, and M. Kutbi, "Existence and uniqueness of fuzzy solutions for the nonlinear second-order fuzzy Volterra integrodifferential equations," Journal of Computational Analysis and Applications, vol. 21, no. 2, pp. 213-227, 2016.

[11] S. Abbasbandy and T. Allahviranloo, "The Adomian decomposition method applied to the fuzzy system of Fredholm integral equations of the second kind," International Journal of Uncertainty, Fuzziness and Knowledge-Based Systems, vol. 14, no. 1, pp. 101-110, 2006.

[12] V. A. Baidosov, "Fuzzy differential inclusions," Journal of Applied Mathematics and Mechanics, vol. 54, no. 1, pp. 8-13, 1990.

[13] E. Hüllermeier, "An approach to modelling and simulation of uncertain dynamical systems," International Journal of Uncertainty, Fuzziness and Knowledge-Based Systems, vol. 5, no. 2, pp. 117-137, 1997.

[14] M. Oberguggenberger and S. Pittschmann, "Differential equations with fuzzy parameters," Mathematical and Computer Modelling of Dynamical Systems, vol. 5, no. 3, pp. 181-202, 1999.

[15] J. J. Buckley and T. Feuring, "Fuzzy differential equations," Fuzzy Sets and Systems, vol. 110, no. 1, pp. 43-54, 2000.

[16] D. Dubois and H. Prade, "Towards fuzzy differential calculus. Part 3: Differentiation," Fuzzy Sets and Systems, vol. 8, no. 3, pp. 225-233, 1982.

[17] M. L. Puri and D. A. Ralescu, "Differentials of fuzzy functions," Journal of Mathematical Analysis and Applications, vol. 91, no. 2, pp. 552-558, 1983.

[18] R. Goetschel Jr. and W. Voxman, "Elementary fuzzy calculus," Fuzzy Sets and Systems, vol. 18, no. 1, pp. 31-43, 1986. 
[19] M. Friedman, M. Ma, and A. Kandel, "Fuzzy Derivatives and Fuzzy Cauchy Problems Using LP Metric," in Fuzzy Logic Foundations and Industrial Applications, vol. 8 of International Series in Intelligent Technologies, pp. 57-72, Springer, Boston, Mass, USA, 1996.

[20] S. Seikkala, "On the fuzzy initial value problem," Fuzzy Sets and Systems, vol. 24, no. 3, pp. 319-330, 1987.

[21] B. Bede and S. G. Gal, "Almost periodic fuzzy-number-valued functions," Fuzzy Sets and Systems, vol. 147, no. 3, pp. 385-403, 2004.

[22] Y. Zhang and G. Wang, "Time domain methods for the solutions of N-order fuzzy differential equations," Fuzzy Sets and Systems, vol. 94, no. 1, pp. 77-92, 1998.

[23] Y. Chalco-Cano, H. Roman-Flores, and M. D. Jimnez-Gamero, "Fuzzy differential equation with-derivative," in Proceedings of the Joint 2009 International Fuzzy Systems Association World Congress and 2009 European Society of Fuzzy Logic and Technology Conference, Lisbon, Portugal, 2009.

[24] L. Stefanini and B. Bede, "Generalized Hukuhara differentiability of interval-valued functions and interval differential equations," Nonlinear Analysis. Theory, Methods \& Applications. An International Multidisciplinary Journal, vol. 71, no. 3-4, pp. 1311-1328, 2009.

[25] B. Bede and L. Stefanini, "Generalized differentiability of fuzzyvalued functions," Fuzzy Sets and Systems, vol. 230, pp. 119-141, 2013.

[26] M. Mazandarani and M. Najariyan, "Differentiability of type-2 fuzzy number-valued functions," Communications in Nonlinear Science and Numerical Simulation, vol. 19, no. 3, pp. 710-725, 2014.

[27] L. C. de Barros and F. Santo Pedro, "Fuzzy differential equations with interactive derivative," Fuzzy Sets and Systems, vol. 309, pp. 64-80, 2017.

[28] M. Mazandarani, N. Pariz, and A. V. Kamyad, "Granular differentiability of fuzzy-number-valued functions," IEEE Transactions on Fuzzy Systems, vol. 26, no. 1, pp. 310-323, 2018.

[29] N. Gasilov, Ş. E. Amrahov, and A. G. Fatullayev, "Solution of linear differential equations with fuzzy boundary values," Fuzzy Sets and Systems, vol. 257, pp. 169-183, 2014.

[30] N. A. Gasilov, A. G. Fatullayev, Ş. E. Amrahov, and A. Khastan, "A new approach to fuzzy initial value problem," Soft Computing, vol. 18, no. 2, pp. 217-225, 2014.

[31] N. A. Gasilov, Ş. E. Amrahov, A. G. Fatullayev, and I. F. Hashimoglu, "Solution method for a boundary value problem with fuzzy forcing function," Information Sciences, vol. 317, pp. 349-368, 2015.

[32] N. A. Gasilov, I. F. Hashimoglu, S. E. Amrahov, and A. G. Fatullayev, "A new approach to non-homogeneous fuzzy initial value problem," CMES. Computer Modeling in Engineering \& Sciences, vol. 85, no. 4, pp. 367-378, 2012.

[33] Ş. E. Amrahov, A. Khastan, N. Gasilov, and A. G. Fatullayev, "Relationship between Bede-Gal differentiable set-valued functions and their associated support functions," Fuzzy Sets and Systems, vol. 295, pp. 57-71, 2016.

[34] O. Abu Arqub, M. Al-Smadi, S. Momani, and T. Hayat, "Numerical solutions of fuzzy differential equations using reproducing kernel Hilbert space method," Soft Computing, 2015.

[35] O. A. Arqub, M. Al-Smadi, S. Momani, and T. Hayat, "Application of reproducing kernel algorithm for solving second-order, two-point fuzzy boundary value problems," Soft Computing, pp. $1-16,2016$.

[36] O. Abu-Arqub, A. El-Ajou, S. Momani, and N. Shawagfeh, "Analytical solutions of fuzzy initial value problems by HAM," Applied Mathematics \& Information Sciences, vol. 7, no. 5, pp. 1903-1919, 2013.

[37] R. E. Moore, Interval Analysis, Prentice-Hall, Englewood Cliffs, NJ, USA, 1966.

[38] S. Markov, "Calculus for interval functions of a real variable," Computing, vol. 22, no. 4, pp. 325-337, 1979.

[39] R. Moore and W. Lodwick, "Interval analysis and fuzzy set theory," Fuzzy Sets and Systems, vol. 135, pp. 5-9, 2003.

[40] M. T. Malinowski, "Interval differential equations with a second type Hukuhara derivative," Applied Mathematics Letters, vol. 24, no. 12, pp. 2118-2123, 2011.

[41] M. T. Malinowski, "Interval Cauchy problem with a second type Hukuhara derivative," Information Sciences, vol. 213, pp. 94-105, 2012.

[42] V. Lupulescu, "Hukuhara differentiability of interval-valued functions and interval differential equations on time scales," Information Sciences, vol. 248, pp. 50-67, 2013.

[43] Y. Chalco-Cano, W. A. Lodwick, and B. Bede, "Single level constraint interval arithmetic," Fuzzy Sets and Systems, vol. 257, pp. 146-168, 2014.

[44] V. Lupulescu, "Fractional calculus for interval-valued functions," Fuzzy Sets and Systems, vol. 265, pp. 63-85, 2015.

[45] S. Salahshour, A. Ahmadian, F. Ismail, and D. Baleanu, "A fractional derivative with non-singular kernel for interval-valued functions under uncertainty," Optik - International Journal for Light and Electron Optics, vol. 130, pp. 273-286, 2017.

[46] S. Salahshour, A. Ahmadian, F. Ismail, D. Baleanu, and N. Senu, "A New fractional derivative for differential equation of fractional order under interval uncertainty," Advances in Mechanical Engineering, vol. 7, no. 12, Article ID 15619138, 2015.

[47] T. M. da Costa, Y. Chalco-Cano, W. A. Lodwick, and G. N. Silva, "A new approach to linear interval differential equations as a first step toward solving fuzzy differential," Fuzzy Sets and Systems, 2017.

[48] N. A. Gasilov and Ş. Emrah Amrahov, "Solving a nonhomogeneous linear system of interval differential equations," Soft Computing, pp. 1-12, 2017.

[49] L. C. Barros, R. C. Bassanezi, and P. A. Tonelli, "Fuzzy modelling in population dynamics," Ecological Modelling, vol. 128, no. 1, pp. 27-33, 2000.

[50] O. Akın and O. Oruc, "A prey predator model with fuzzy initial values," Hacettepe Journal of Mathematics and Statistics, vol. 41, no. 3, pp. 387-395, 2012.

[51] H. Zarei, A. V. Kamyad, and A. A. Heydari, "Fuzzy modeling and control of HIV infection," Computational and Mathematical Methods in Medicine, vol. 2012, Article ID 893474, 17 pages, 2012.

[52] G. L. Diniz, J. F. R. Fernandes, J. F. C. A. Meyer, and L. C. Barros, "A fuzzy Cauchy problem modelling the decay of the biochemical oxygen demand in water," in Proceedings of the Joint 9th IFSA World Congress and 20th NAFIPS International Conference, pp. 512-516, Vancouver, Canada, 2002.

[53] H. N. Nounou, M. N. Nounou, N. Meskin, A. Datta, and E. R. Dougherty, "Fuzzy intervention in biological phenomena," IEEE Transactions on Computational Biology and Bioinformatics, vol. 9, no. 6, pp. 1819-1825, 2012.

[54] K. Barzinji, N. Maan, and N. Aris, "Fuzzy delay predator-prey system: existence theorem and oscillation property of solution," 
International Journal of Mathematical Analysis, vol. 8, no. 17-20, pp. 829-847, 2014.

[55] R. M. Jafelice, L. C. de Barros, R. C. Bassanezi, and F. Gomide, "Fuzzy modeling in symptomatic HIV virus infected population," Bulletin of Mathematical Biology, vol. 66, no. 6, pp. 1597$1620,2004$.

[56] A. H. A. Omar and Y. A. Hasan, "The interaction of predator prey with uncertain initial population sizes," Journal of Quality Measurement and Analysis JQMA, vol. 7, no. 2, pp. 75-83, 2011.

[57] M. da Silva Peixoto, L. C. de Barros, and R. C. Bassanezi, "Predator-prey fuzzy model," Ecological Modelling, vol. 214, no. 1, pp. 39-44, 2008.

[58] M. Z. Ahmad and M. K. Hasan, "Modeling of biological populations using fuzzy differential equations," International Journal of Modern Physics: Conference Series, vol. 9, pp. 354-363, 2012.

[59] M. Z. Ahmad and B. De Baets, A Predator-Prey Model with Fuzzy Initial Populations, IFSA-EUSFLAT 2009.

[60] M. Najariyan, M. H. Farahi, and M. Alavian, "Optimal control of HIV infection by using fuzzy dynamical systems," The Journal of Mathematics and Computer Science, vol. 2, no. 4, pp. 639-649, 2011.

[61] N. Maan, K. Barzinji, and N. Aris, "Fuzzy delay differential equation in predator-prey interaction: analysis on stability of steady state," in Proceedings of the 2013 World Congress on Engineering, WCE 2013, vol. 1, London, UK, 2013.

[62] D. Pal and G. S. Mahapatra, "A bioeconomic modeling of twoprey and one-predator fishery model with optimal harvesting policy through hybridization approach," Applied Mathematics and Computation, vol. 242, pp. 748-763, 2014.

[63] D. Pal, G. S. Mahaptra, and G. P. Samanta, "Optimal harvesting of prey-predator system with interval biological parameters: a bioeconomic model," Mathematical Biosciences, vol. 241, no. 2, pp. 181-187, 2013.

[64] P. Pandit and P. Singh, "Prey predator model with fuzzy initial conditions," International Journal of Engineering and Innovative Technology (IJEIT), vol. 3, no. 12, 2014.

[65] D. Pal, G. S. Mahaptra, and G. P. Samanta, "Quota harvesting model for a single species population under fuzziness," IJMS, vol. 12, no. 1-2, pp. 33-46, 2013.

[66] S. Tapaswini and S. Chakraverty, "Numerical solution of fuzzy arbitrary order predator-prey equations," Applications and Applied Mathematics. An International Journal, vol. 8, no. 2, pp. 647-672, 2013.

[67] D. Pal, G. S. Mahapatra, and G. P. Samanta, "A Proportional harvesting dynamical model with fuzzy intrinsic growth rate and harvesting quantity," Pacific-Asian Journal of Mathematics, vol. 6, no. 2, pp. 199-213, 2012.

[68] O. A. Arqub and A. El-Ajou, "Solution of the fractional epidemic model by homotopy analysis method," Journal of King Saud University - Science, vol. 25, no. 1, pp. 73-81, 2013.

[69] S. Sharma and G. P. Samanta, "Optimal harvesting of a two species competition model with imprecise biological parameters," Nonlinear Dynamics, 2014.

[70] L. C. Barros, R. C. Bassanezi, R. Z. G. Oliveira, and M. B. F. Leite, "A disease evolution model with uncertain parameters," in Proceedings of the IFSA World Congress and 20th NAFIPS International Conference, vol. 3, pp. 1626-1630, 2001.

[71] V. M. Cabral and L. C. Barros, "Fuzzy differential equation with completely correlated parameters," Fuzzy Sets and Systems, vol. 265, pp. 86-98, 2015.
[72] R. P. Agarwal, D. O’Regan, and V. Lakshmikantham, "A stacking theorem approach for fuzzy differential equations," Nonlinear Analysis. Theory, Methods \& Applications. An International Multidisciplinary Journal, vol. 55, no. 3, pp. 299-312, 2003.

[73] R. P. Agarwal, D. O’Regan, and V. Lakshmikantham, "Viability theory and fuzzy differential equations," Fuzzy Sets and Systems, vol. 151, no. 3, pp. 563-580, 2005.

[74] P. Diamond, "Stability and periodicity in fuzzy differential equations," IEEE Transactions on Fuzzy Systems, vol. 8, no. 5, pp. 583-590, 2000.

[75] P. Diamond, "Theory and applications of fuzzy volterra integral equations," IEEE Transactions on Fuzzy Systems, vol. 10, no. 1, pp. 97-102, 2002.

[76] V. Laksmikantham, S. Leela, and A. S. Vatsala, "Interconnection between set and fuzzy differential equations," Nonlinear Analysis. Theory, Methods \& Applications. An International Multidisciplinary Journal, vol. 54, no. 2, pp. 351-360, 2003.

[77] V. Lakshmikantham and A. A. Tolstonogov, "Existence and interrelation between set and fuzzy differential equations," Nonlinear Analysis. Theory, Methods \& Applications. An International Multidisciplinary Journal, vol. 55, no. 3, pp. 255-268, 2003.

[78] P. Diamond, "Brief note on the variation of constants formula for fuzzy differential equations," Fuzzy Sets and Systems, vol. 129, no. 1, pp. 65-71, 2002.

[79] P. Diamond and P. Watson, "Regularity of solution sets for differential inclusions quasi-concave in a parameter," Applied Mathematics Letters, vol. 13, no. 1, pp. 31-35, 2000.

[80] E. Hüllermeier, "Numerical methods for fuzzy initial value problems," International Journal of Uncertainty, Fuzziness and Knowledge-Based Systems, vol. 7, no. 5, pp. 439-461, 1999.

[81] M. Ma, M. Friedman, and A. Kandel, "Numerical solutions of fuzzy differential equations," Fuzzy Sets and Systems, vol. 105, no. 1, pp. 133-138, 1999.

[82] M. Z. Ahmad, M. K. Hasan, and B. De Baets, "Analytical and numerical solutions of fuzzy differential equations," Information Sciences, vol. 236, pp. 156-167, 2013.

[83] M. Z. Ahmad and M. K. Hasan, "A new fuzzy version of Euler's method for solving differential equations with fuzzy initial values," Sains Malaysiana, vol. 40, no. 6, pp. 651-657, 2011.

[84] M. Z. Ahmad, M. K. Hasan, and S. Abbasbandy, "Solving fuzzy fractional differential equations using Zadeh's extension principle," The Scientific World Journal, vol. 2013, Article ID 454969, 11 pages, 2013.

[85] B. Bede and S. G. Gal, "Generalizations of the differentiability of fuzzy-number-valued functions with applications to fuzzy differential equations," Fuzzy Sets and Systems, vol. 151, no. 3, pp. 581-599, 2005.

[86] B. Bede, I. J. Rudas, and A. L. Bencsik, "First order linear fuzzy differential equations under generalized differentiability," Information Sciences, vol. 177, no. 7, pp. 1648-1662, 2007.

[87] L. Stefanini and B. Bede, "Generalized fuzzy differentiability with LU-parametric representation," Fuzzy Sets and Systems, vol. 257, pp. 184-203, 2014.

[88] Y. Chalco-Cano and H. Román-Flores, "On new solutions of fuzzy differential equations," Chaos, Solitons \& Fractals, vol. 38, no. 1, pp. 112-119, 2008.

[89] Y. Chalco-Cano and H. Román-Flores, "Comparation between some approaches to solve fuzzy differential equations," Fuzzy Sets and Systems, vol. 160, no. 11, pp. 1517-1527, 2009. 
[90] E. J. Villamizar-Roa, V. Angulo-Castillo, and Y. Chalco-Cano, "Existence of solutions to fuzzy differential equations with generalized Hukuhara derivative via contractive-like mapping principles," Fuzzy Sets and Systems, vol. 265, pp. 24-38, 2015.

[91] A. Ahmadian, H. S. Chan, S. Salahshour, and V. Vaitheeswaran, "FTFBE: A numerical approximation for fuzzy time-fractional Bloch equation," in Proceedings of the 2014 IEEE International Conference on Fuzzy Systems, FUZZ-IEEE 2014, pp. 418-423, China, July 2014. 


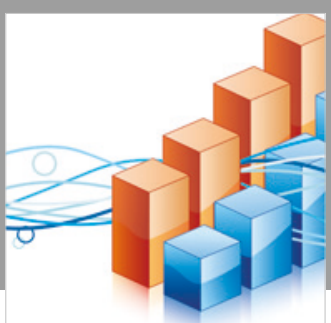

Advances in

Operations Research

\section{-n-m}
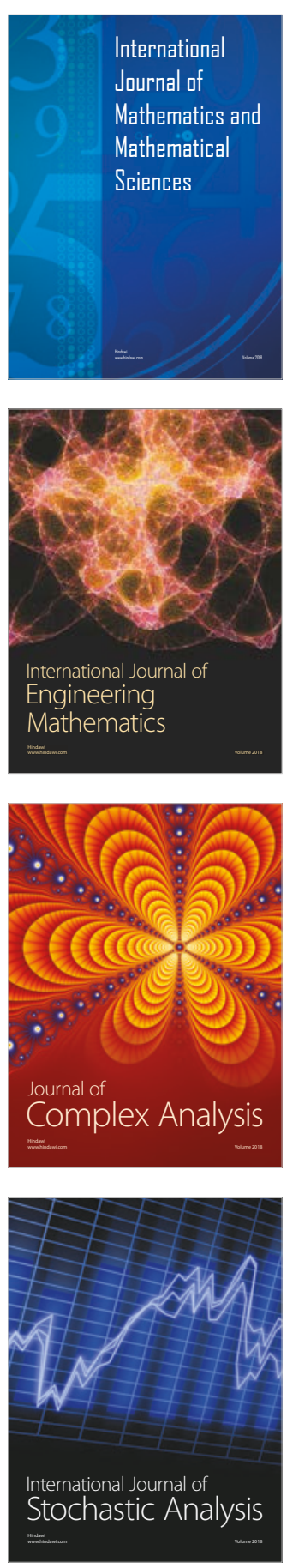
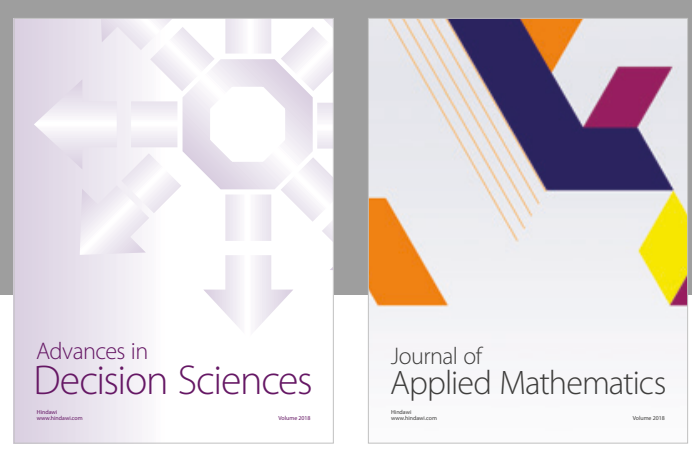

Journal of

Applied Mathematics
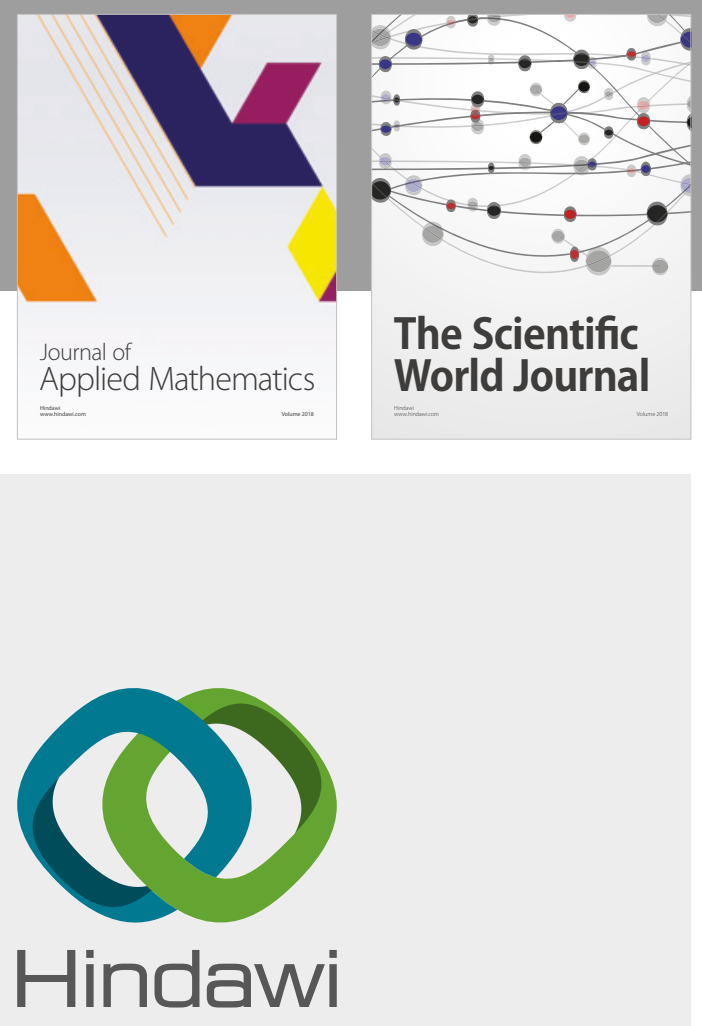

Submit your manuscripts at

www.hindawi.com

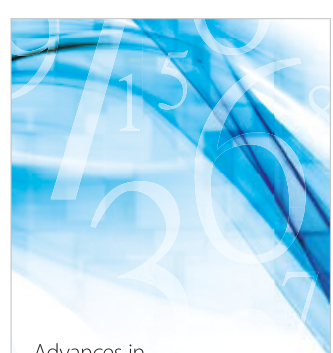

Advances in
Numerical Analysis
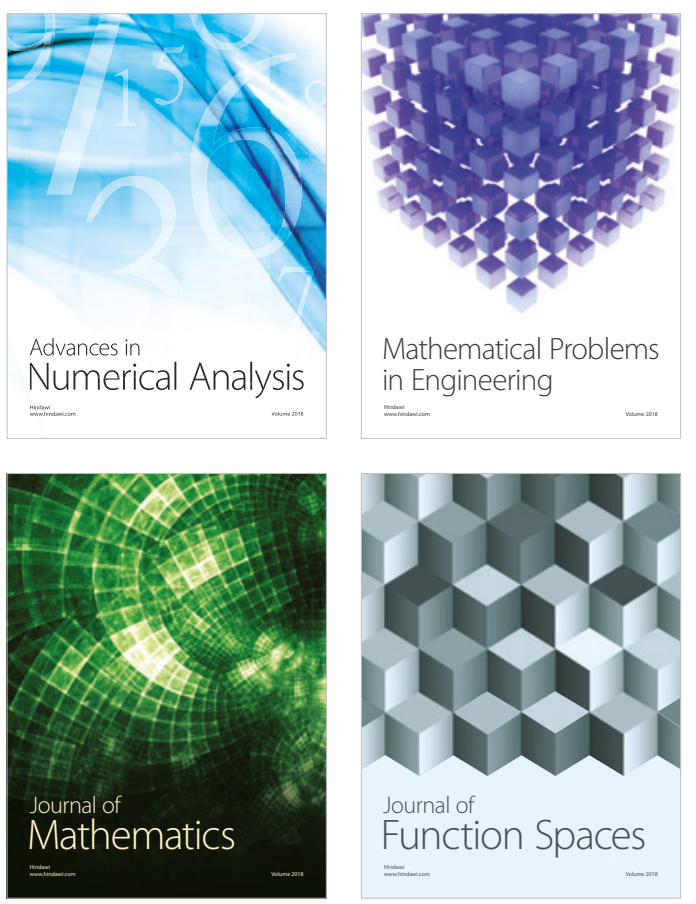

Mathematical Problems in Engineering

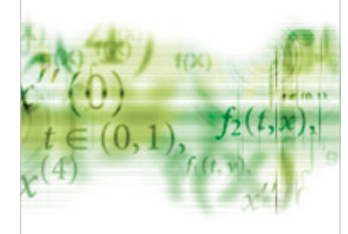

International Journal of

Differential Equations

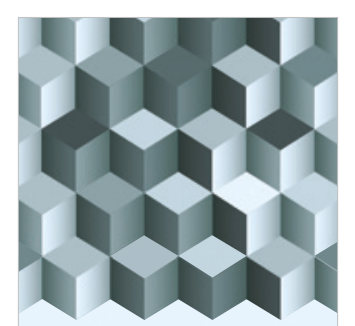

Journal of

Function Spaces
The Scientific

World Journal

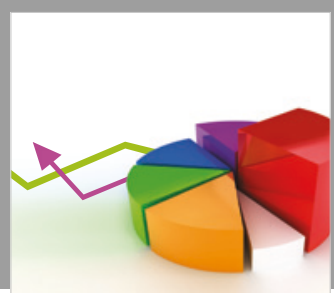

Journal of

Probability and Statistics
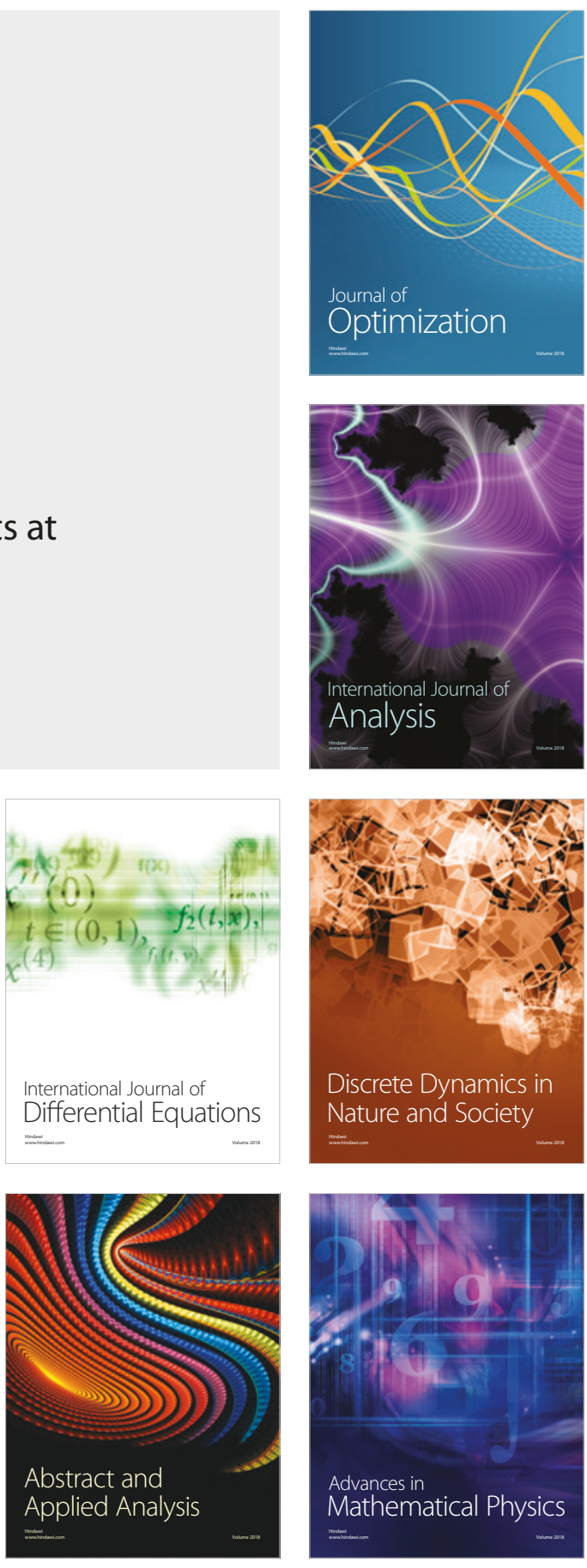